Federal Reserve Bank of Dallas

Globalization and Monetary Policy Institute

Working Paper No. 107

http://www.dallasfed.org/assets/documents/institute/wpapers/2012/0107.pdf

\title{
Liquidity, Risk and the Global Transmission of the 2007-08 Financial Crisis and the 2010-11 Sovereign Debt Crisis ${ }^{*}$
}

\author{
Alexander Chudik \\ Federal Reserve Bank of Dallas \\ CIMF \\ Marcel Fratzscher \\ European Central Bank \\ CEPR \\ January 2012
}

\begin{abstract}
The paper analyses the transmission of liquidity shocks and risk shocks to global financial markets. Using a Global VAR methodology, the findings reveal fundamental differences in the transmission strength and pattern between the 2007-08 financial crisis and the 2010-11 sovereign debt crisis. Unlike in the former crisis, emerging market economies have become much more resilient to adverse shocks in 2010-11. Moreover, a fight-to-safety phenomenon across asset classes has become particularly strong during the 2010-11 sovereign debt crisis, with risk shocks driving down bond yields in key advanced economies. The paper relates this evolving transmission pattern to portfolio choice decisions by investors and finds that countries' sovereign rating, quality of institutions and their financial exposure are determinants of cross-country differences in the transmission.
\end{abstract}

JEL codes: E44, F3, C5

\footnotetext{
*Alexander Chudik, Federal Reserve Bank of Dallas, Research Department, 2200 N. Pearl Street, Dallas,TX 75201. 214-922-5769. Alexander.chudik@dal.frb.org. Marcel Fratzscher, European Central Bank, Kaiserstraße 29, D - 60311 Frankfurt am Main, Germany. +49-69-1344-6871. marcel.fratzscher@ecb.int. We would like to thank participants of the July 2011 conference in honor of Prof. Hashem Pesaran for helpful comments and discussions, and Thomas Kostka for his help with compiling the data on capital flows. The views in this paper are those of the authors and do not necessarily reflect the views of the European Central Bank, the Federal Reserve Bank of Dallas or the Federal Reserve System.
} 


\section{Introduction}

Global financial markets and capital flows have been tremendously volatile ever since the onset of the global financial crisis in August 2007. Even after the global financial crisis of 2007-08 started abating, the European sovereign debt crisis, concerns about US debt and worries about a repeated global economic downturn have induced a sizeable adjustment in asset prices and in the allocation of liquidity in 2010 and 2011. Yet these two crises have affected countries and asset markets very differently. Despite having the US as an origin, the 2007-08 crisis affected asset prices and capital flows to emerging market economies (EMEs) more strongly than those in advanced economies (AEs) as capital fled EMEs, triggering a collapse in EME asset prices and exchange rates, while buffering the decline in asset prices and even inducing an exchange rate appreciation in many AEs. By contrast, the 2010-11 crisis has seen a remarkable resilience of EMEs, both in terms of the effect on the real economy and on financial markets.

Many observers and policy-makers have pointed to the importance of shocks to liquidity and to risk in explaining the dynamics of both the global crisis of 2007-08 and the 2010-11 debt crisis. In particular the squeeze of liquidity in 2008, which implied a drying up of liquidity among financial institutions, forced many banks and investors to repatriate capital to finance investment and meet redemption calls, thus severely restricting the capital available to the real side of the economy and triggering a major global recession (Adrian and Shin (2010), Borio (2009), Tirole (2010)). Moreover, the rise in risk and risk aversion in 2007-08 induced a flight-to-safety phenomenon, which not only entailed a rebalancing towards safer asset classes, but also a massive capital flight from supposedly riskier countries - foremost EMEs - to advanced economies. These large capital outflows worsened the real and financial impact of the 2007-08 crisis on EMEs in particular. However, such a flightto-safety phenomenon out of EMEs has been largely absent in 2010-11, and in fact capital has continued to pour into EMEs.

This paper analyses the global transmission of the 2007-08 financial crisis and the 2010-11 sovereign debt crisis via shocks to liquidity and shocks to risk. The objective of the paper is threefold. First, we analyse how shocks to liquidity and risk are transmitted to financial markets globally and how they help us understand the dynamics of the two different crisis episodes. We 
don't only look at a broad set of 28 EMEs and AEs, but importantly, we analyse the response of asset prices (equity markets and bond yields) as well as of exchange rates and capital flows in equities and bonds in order to gauge the functioning of the transmission channels. A strength of the analysis is that we are able to use relatively high-frequency weekly data to gauge the transmission of shocks through global financial markets, employing also relatively new data on high-frequency private portfolio capital flows.

Second, we specifically analyse how the 2007-08 financial crisis and the 2010-11 sovereign debt crisis have been different, both in the scope with which different countries have been affected and in the way shocks to risk and liquidity have been transmitted. And third, we attempt to shed light on the portfolio decisions by investors, and their determinants, during the two crises by analysing portfolio choice of investors both geographically (across countries) and across asset classes in order to understand the differences across crisis episodes.

An simultaneous empirical analysis of asset prices, exchange rates as well as capital flows across 28 countries is far from straightforward. Altogether we have 144 endogenously related variables. Such a large dimensionality renders traditional VAR models inapplicable. We employ a relatively novel, so called infinite-dimensional VAR methodology introduced by Chudik and Pesaran (2011b) and later extended by Chudik and Pesaran (2011a). This methodology allows us to treat all variables as endogenous, which is arguably a very important advantage for our purpose. Restrictions to overcome the dimensionality problem in this approach are based on an economically intuitive concept and allow for rich spatial and temporal interactions among variables. In particular, we allow for the US to potentially have a dominant influence on other countries, and we also allow for other (unknown) sources of strong cross-section dependencies besides the dominant US variables. Neighborhood effects (i.e. lags of other variables entering the relation for a given unit) and an unspecified weak-form cross-section dependence of innovations are also fully accounted for. ${ }^{1}$ The distinction between the weak and strong cross-section dependence also helps us to distinguish global shocks (which could originate in the US) from local idiosyncratic shocks. To distinguish between different types of global shocks, we combine several pieces of information in the form of restrictions on the signs of impulse responses.

The empirical analysis highlights four key findings. First, the transmission of liquidity shocks and risk shocks is highly heterogeneous - across countries, across asset classes and over time.

\footnotetext{
${ }^{1}$ See Chudik, Tosetti, and Pesaran (2011) for definition of weak and strong cross section dependence.
} 
Shocks to liquidity and to risk exhibited much larger effects on asset prices and on capital flows during the 2007-08 financial crisis than either in the pre-2007 period or the 2010-11 sovereign debt crisis, highlighting that these two crises have (so far) been very different in the way markets have responded. There are also important cross-country differences. EMEs have been affected much more strongly - both in terms of asset prices and capital flows - by shocks during the 2007-08 crisis, often exhibiting a sensitivity to shocks that has been twice as large as that for AEs. By contrast, EME markets did not respond differently to shocks in 2010-11 than in the more tranquil pre-2007 period, suggesting that there has be some de-coupling of EMEs from AEs in 2010 and 2011 relative to previous crises.

Second, the findings of the analysis yield clear evidence of a strong geographic flight-to-safety phenomenon during the 2007-08 financial crisis, but much less compelling evidence of such a pattern since 2009. For instance, in the 2007-08 crisis a rise in risk triggered not only a decline in bond yields in the US and other AEs, but it raised bond yields in EMEs dramatically, caused an exchange rate depreciation and induced large net capital outflows for EMEs. By contrast, in 2010-11 EME bond yields have hardly responded to such shocks, while the drop in equity returns and portfolio investment in equities and in bonds has been very similar for EMEs as for AEs.

Third, the analysis uncovers an interesting pattern of portfolio choice among investors. An important part of the literature on portfolio choice has been investigating whether investor decisions are driven by a portfolio rebalancing motive (building on the seminal work by Branson and Henderson (1985)) where market incompleteness and risk induce investors to aim for a stable allocation across assets in their portfolios - thus implying a negative correlation between returns and investment (flows) into a given asset. On the other hand, another strand of the literature has emphasised the role of a return chasing motive (building on the work by Bohn and Tesar (1996), and Brennan and Cao (1997)) which implies a positive correlation between returns and investment of a financial asset. The analysis in the present paper finds evidence for a portfolio rebalancing motive for relatively safe financial assets - primarily for bonds in AEs - implying a negative correlation between returns and flows into these assets conditional on shocks to risk. By contrast, there is a mostly positive correlation between returns and flows for relatively more risk assets - portfolio equity assets in AEs and especially EME equities and bonds - akin to a return chasing motive. We link these findings to the flight-to-safety phenomenon observed in particular during the 2007-08 
financial crisis.

Fourth and finally, the paper attempts to identify some of the determinants that explain the differences of the transmission of shocks across countries. In particular, we analyze to what extent it was the external exposure - either through trade linkages or through financial linkages - and to what extent it was idiosyncratic, country-specific characteristics - such as related to countries' macroeconomic fundamentals and perceived riskiness - that made countries vulnerable to different types of external shocks. For this purpose, we employ a Bayesian Averaging of Classical Estimates (BACE) approach of Sala-i-Martin et al. (2004). It combines the averaging of cross-section estimates across models estimated by classical least squares, and is in particular useful for understanding which variables in a large set of potential determinants might have played a role. We find that the transmission of risk and liquidity shocks across countries was influenced by countries' financial exposure to the US. As a second set of factors, countries' exposure to liquidity and risk shocks is dependent on the strength of countries' own fundamentals. Those economies with a poor sovereign rating and worse economic and political institutions were substantially more affected by risk and liquidity shocks in both crises. These findings have important implications, not just for our understanding of the global transmission of the crisis, but also about what economic policy can do to shield the domestic economy from global shocks.

We stress a number of caveats and limitations to the analysis of the paper. Importantly, we limit our analysis to two types of shocks - shocks to liquidity conditions and to risk - while ignoring other shocks which have been relevant during the two crises. Such shocks may be related to economic activity, the conjunctural situation of a country, or they be related to systemic events such as the collapse of financial institutions. Moreover, we limit our analysis to shocks that are mainly global in nature, while we do not investigate the impact of idiosyncratic shocks to any of the 28 economies of the analysis. All these raise interesting and important issues, but ones that go beyond the scope of this paper.

The paper relates to different strands of the literature. One such strand is the literature on the transmission of the 2007-08 global financial crisis, which has given particular prominence to the role of liquidity shocks (e.g. Brunnermeier and Pedersen (2009); Calomiris (2008) and Taylor (2009)). An emerging literature analyses the global transmission of the crisis and the question through what channels and via which market segments the transmission took place, stressing the 
relevance of liquidity and financial constraints (e.g. Tong and Wei (2009)) or of equity and FX markets (Bekaert et al. (2011), Fratzscher (2009)).

More generally, the issues we address relate closely to a vast literature on modelling the international transmission mechanism in financial markets. Important recent work is by Diebold and Yilmaz (2009) who propose a spillover index derived from a VAR analysis of a broad set of equity markets, or Dungey and Martin (2007), Forbes and Rigobon (2002), Bekaert et al. (2005) who investigate the role of contagion for a broad set of countries and market segments. Ehrmann et al. (2010) and Ehrmann and Fratzscher (2005) show that such an international transmission may occur not only within asset classes but also across asset classes. As to the transmission channels, Forbes and Chinn (2004) stress the role of real and trade linkages through which some countries may be more strongly affected by global common or regional shocks, while Fratzscher (2011) highlights that both push factors (such as related to global risk and liquidity conditions) as well as pull factors (country-specific fundamentals and institutions) have played an important role in explaining the pattern of global capital flows. Chudik and Fratzscher (2011) also analyse the transmission of global shocks, but their focus is more narrowly on equity and money markets, while excluding exchange rates, bond markets and capital flows from the analysis.

A third strand relates to the methodology and the literature on Global VARs. Pesaran et al. (2004) provided the seminal contribution and proposed a framework for modelling international linkages in a Global VAR setting, which was then applied and extended in a number of papers, including Dées, di Mauro, Pesaran, and Smith (2007), Pesaran, Schuermann, and Treutler (2007), and Pesaran, Smith, and Smith (2007). Chudik and Pesaran (2011a,b) provided a methodological foundation of the conditional models estimated in a GVAR framework, treating all variables as endogenously determined in one global system. We also follow these latter two papers to specify our models, allowing for a very rich spatio-temporal linkages among markets and economies.

The paper is structured as follows. Section 2 outlines the empirical methodology, including the identification of shocks to risk and to liquidity. The various data series and sources are discussed in Section 3. Section 4 then presents the findings of the empirical analysis, starting with the results based on the impulse response functions and concluding with the findings about the determinants of the global transmission process to different countries and market segments. Section 5 summarises the main points and concludes. 


\section{A global model of financial markets}

In this section, we present the empirical methodology employed to analyse the transmission of shocks to liquidity and risk in a large system with a large set of countries. The section also outlines how the impulse response functions are specified and used to analyse the transmission mechanism of shocks.

\subsection{The model}

Let $\mathbf{x}_{i t}$ denote a vector of $k_{i}$ domestic variables of country $i=1,2, \ldots, N$ in period $t=1,2, \ldots, T$. All, domestic and foreign, variables are jointly determined and it is supposed that the vector of all $k=\sum_{i=1}^{N} k_{i}$ variables in the global system, denoted as $\mathbf{x}_{t}=\left(\mathbf{x}_{1 t}^{\prime}, \ldots, \mathbf{x}_{N t}^{\prime}\right)^{\prime}$, is given by the following factor-augmented VAR model:

$$
\mathbf{x}_{t}=\mathbf{\Phi} \mathbf{x}_{t-1}+\boldsymbol{\Gamma} \mathbf{f}_{t}+\mathbf{u}_{t}
$$

where $\boldsymbol{\Phi}$ is (large) $k \times k$ matrix of coefficients, $\mathbf{u}_{t}=\left(\mathbf{u}_{1 t}^{\prime}, \ldots, \mathbf{u}_{N t}^{\prime}\right)^{\prime}$ is $k \times 1$ vector of reduced form errors, $\boldsymbol{\Gamma}$ is $k \times m$ matrix of factor loadings, $m$ is (unknown) number of unobserved common factors, and $\mathbf{f}_{t}$ is $m \times 1$ vector of unobserved common factors given by the following VAR model:

$$
\mathbf{f}_{t}=\mathbf{\Psi} \mathbf{f}_{t-1}+\mathbf{v}_{t}
$$

We abstract here in the notation from higher order lags and from deterministic terms to keep the exposition simpler.

Without any loss of generality, denote the US as a country $N$ throughout the paper. Our set of endogenous variables is:

$$
x_{i t}=\left(i_{i t}, r_{i t}, e_{i t}, \kappa_{i t}, \varkappa_{i t}\right)^{\prime}, \text { for } i=1,2, \ldots, N-1 \text {, }
$$

that is for all economies except the US, and

$$
\mathbf{x}_{N t}=\left(i_{N t}, r_{N t}, e_{N t}, \kappa_{N t}, \varkappa_{N t}, v i x_{t}, t e d_{t}\right)^{\prime}
$$

for the US economy, where $i_{i t}$ denotes the first difference in long term government bond yields (in country $i$ and period $t$ ), $r_{i t}$ denotes stock market returns, $e_{i t}$ is the nominal effective exchange rate 
return, $\kappa_{i t}$ denotes the net capital inflows into bonds markets of country $i, \varkappa_{N t}$ denotes the net capital inflows in the stock markets of country $i, v i x_{t}$ is the first difference in the log of the VIX index, and $t e d_{t}$ is the the US ted spread. Thus $k_{i}=5$ for $i<N$, and $k_{N}=7$.

\subsection{Solution to the curse of dimensionality}

The drawback of the high-dimensional model (1)-(2) is that the reduced form coefficients cannot be estimated by conventional methods since the number of variables, $k$, is large (of comparable size to the time dimension), and the number of unknown coefficients grows at a quadratic rate with $k$. We restore to the method proposed by Chudik and Pesaran (2011a,b) to deal with this proliferation of parameters, also known as the 'curse of dimensionality' problem. In line with this approach, we assume that the coefficient matrix can be partitioned as

$$
\boldsymbol{\Phi}=\boldsymbol{\Phi}_{a}+\boldsymbol{\Phi}_{b}
$$

where $\boldsymbol{\Phi}_{a}$ captures all neighborhood relationships as well as possible (global) dominance of selected variables and is given by

$$
\Phi_{a}=\mathbf{D S}
$$

where $\mathbf{D}$ is block-diagonal matrix:

$$
\underset{k \times d}{\mathbf{D}}=\left(\begin{array}{cccc}
\mathbf{D}_{1} & \mathbf{0} & \cdots & \mathbf{0} \\
\mathbf{0} & \mathbf{D}_{2} & & \mathbf{0} \\
\vdots & & \ddots & \\
\mathbf{0} & \mathbf{0} & & \mathbf{D}_{N}
\end{array}\right)
$$

with $\mathbf{D}_{i}$ having dimensions $k_{i} \times d_{i}, \mathbf{S}$ is known $d \times k$ matrix that defines neighbors and/or dominance of individual units, and it is conveniently partitioned as $\mathbf{S}=\left[\mathbf{S}_{1}, \mathbf{S}_{2}, \ldots, \mathbf{S}_{N}\right]^{\prime}$ below, where $\mathbf{S}_{i}$ is $k \times d_{i}$. The matrix $\boldsymbol{\Phi}_{b}$ captures the non-neighbor relationships and its elements, denoted as $\phi_{b, i j}$, are uniformly bounded by an $O\left(k^{-1}\right)$ variable, in particular

$$
\left|\phi_{b, i j}\right| \leq \frac{K}{k}, \text { for all } i \text { and } j
$$


where the constant $K$ does not depend on the number of cross section units. The non-neighbor relationships could be motivated by diversification motives of economic agents, or could simply arise from an error in the specification of spatial weigh matrices in $\mathbf{S}$, see Chudik and Pesaran (2011b) for further details.

The construction of $\mathbf{S}$ is crucial in this framework. We construct this matrix based on the following three principles: $(i)$ we allow for dominance of the US variables, that is we do not restrict any of coefficients corresponding to direct contemporaneous or lagged influence of the US, $(i i)$ own lags of domestic variables are also selected, and finally ( $i i i)$ we allow for neighbors in form of spatial weighted averages of foreign trading partners, where the weights are constructed from data on bilateral portfolio holdings. The matrix $\mathbf{S}=\left[\mathbf{S}_{i}^{\prime}\right]$ is thus given by

$$
\mathbf{S}_{i}=\left(\mathbf{E}_{1}, \mathbf{E}_{i}, \mathbf{W}_{i}\right), \text { for } i=1,2, \ldots, N-1,
$$

and

$$
\mathbf{S}_{N}=\mathbf{E}_{N}
$$

for the US, where $\mathbf{E}_{i}$, for $i=1,2, \ldots, N$, is $k \times k_{i}$ selection matrix that selects the vector of domestic variables, in particular $\mathbf{E}_{i}^{\prime} \mathbf{x}_{t}=\mathbf{x}_{i t}$. The US is not assumed to have any neighbors, more on this below.

Chudik and Pesaran (2011a,b) establish that under the assumptions discussed above and few other regularity conditions (see Theorem 2 in Chudik and Pesaran (2011b), and Theorem 1 in Chudik and Pesaran (2011a)), it is possible to estimate the coefficients corresponding to the neighbors and own lags by Augmented Least Squares (ALS) using the following (augmented) countryspecific regressions:

$$
\mathbf{x}_{i t}=\underbrace{\boldsymbol{\Phi}_{i i} \mathbf{x}_{i, t-1}}_{\text {Own lags }}+\underbrace{\mathbf{A}_{i 0} \mathbf{x}_{N t}+\sum_{\ell=1}^{q} \mathbf{A}_{i \ell} \mathbf{x}_{N, t-\ell}}_{\text {Dominant units }}+\underbrace{\mathbf{B}_{i} \overline{\mathbf{x}}_{w, i, t-1}^{\prime}}_{\text {Neighbor lags }}+\underbrace{\mathbf{H}_{i 0} \overline{\mathbf{x}}_{t}+\sum_{\ell=1}^{q} \mathbf{H}_{i \ell} \overline{\mathbf{x}}_{t-\ell}}_{\text {Granular cross section averages }}+\mathbf{e}_{i t},
$$

for $i=1,2, \ldots, N-1$, where the truncation lag $q$ has to be selected as an appropriate increasing function of the sample size. Furthermore,

$$
\mathbf{e}_{i t}-E\left(\mathbf{u}_{i t} \mid \mathbf{u}_{N t}\right) \stackrel{q . m .}{\rightarrow} 0
$$


as $k, q \rightarrow \infty$, and the equation (3) with $q \rightarrow \infty$ is large $k$ representation of the variable $\mathbf{x}_{i t}$ in the high dimensional model given by (1)-(2). It is interesting to highlight that despite one lag assumed in the VAR model (1), the dominant units enter ALS regressions with more lags. The intuition behind this result and the discussion about identification issues in the presence of dominant unit are provided in Chudik and Pesaran (2011b).

The granular cross-section averages, denoted as $\overline{\mathbf{x}}_{t}$, are used to take the effects of unobserved common factors into account. The original idea of using the cross section averages to take into account effects of unobserved common factors in the context of panel estimation was proposed by Pesaran (2006) and this idea was later explored in the context of high dimensional VARs by Chudik and Pesaran (2011b). We simply use the following arithmetic averages:

$$
\overline{\mathbf{x}}_{t}=\frac{1}{N-1} \sum_{i=1}^{N-1} \mathbf{x}_{i t}
$$

to take into account the effects of unobserved common factors, which is in general sufficient when $m$ does not exceed the dimension of $\overline{\mathbf{x}}_{t}$, in our case 5 .

The dominant unit has to be treated differently from the remaining units, due to its nonnegligible impact on the rest of the system as a whole and the corresponding nonnegligible secondround effect on the dominant unit itself. As suggested by Chudik and Pesaran (2011a), we estimate the following ALS regression for the US variables:

$$
\left(\begin{array}{c}
\mathbf{x}_{N t} \\
\overline{\mathbf{x}}_{t}
\end{array}\right)=\sum_{\ell=1}^{q} \mathbf{D}_{\ell}\left(\begin{array}{c}
\mathbf{x}_{N, t-\ell} \\
\overline{\mathbf{x}}_{t-\ell}
\end{array}\right) \mathbf{e}_{N t}
$$

where the US variables are treated as endogenously determined with the vector of cross section averages. System of estimated equations (3) and (4) turns out to be asymptotically sufficient description of the underlying high-dimensional model (1)-(2) for the purpose of impulse response analysis or forecasting. Let us define $\mathbf{z}_{t}=\left(\mathbf{x}_{t}^{\prime}, \overline{\mathbf{x}}_{t}^{\prime}\right)^{\prime}$. Stacking equations (3)-(4) yields the following large VAR model,

$$
\mathbf{C}_{0} \mathbf{z}_{t}=\sum_{\ell=1}^{q} \mathbf{C}_{\ell} \mathbf{z}_{t-\ell}+\mathbf{e}_{t}
$$


where the $k+n \times k+n$ dimensional coefficient matrices are

$$
\mathbf{C}_{0}=\left(\begin{array}{ccc}
\mathbf{I}_{(N-1) n} & -\mathbf{A}_{0} & -\mathbf{H}_{0} \\
\mathbf{0} & \mathbf{I}_{k_{N}} & \mathbf{0} \\
\mathbf{0} & \mathbf{0} & \mathbf{I}_{n}
\end{array}\right), \mathbf{C}_{\ell}=\left(\begin{array}{c|cc}
\mathbf{\Xi}_{\ell} & -\mathbf{A}_{\ell}-\mathbf{H}_{\ell} \\
\hline \mathbf{0} & \mathbf{D}_{\ell}
\end{array}\right), \text { for } \ell>0
$$

in which $\Xi_{\ell}=0$ for $\ell>1$,

$$
\Xi_{1}=\left(\begin{array}{cccc}
\boldsymbol{\Phi}_{11} & \mathbf{0} & \ldots & \mathbf{0} \\
\mathbf{0} & \boldsymbol{\Phi}_{11} & & \mathbf{0} \\
\vdots & & \ddots & \\
\mathbf{0} & \mathbf{0} & & \boldsymbol{\Phi}_{N-1, N-1}
\end{array}\right), \mathbf{A}_{\ell}=\left(\begin{array}{c}
\mathbf{A}_{\ell 1} \\
\mathbf{A}_{\ell 2} \\
\vdots \\
\mathbf{A}_{\ell, N-1}
\end{array}\right) \text {, and } \mathbf{H}_{\ell}=\left(\begin{array}{c}
\mathbf{H}_{\ell 1} \\
\mathbf{H}_{\ell 2} \\
\vdots \\
\mathbf{H}_{\ell, N-1}
\end{array}\right) \text { for all } \ell
$$

\subsection{Impulse-response analysis}

This paper focuses on the impact of global shocks and their transmission across countries, market segments, and time. There are $k_{N}+m$ global shocks in the system (1)-(2), consisting of the $k_{N}$ US innovations in vector $\mathbf{u}_{N t}$ and $m$ unobserved common factor innovations in the vector $\mathbf{v}_{t}$. These innovations are spanned by the reduced form errors estimated based on the marginal model (4), provided that $m$ is not larger than the number of cross section averages $(k)$. As a result of the dominance of the US variables, the reduced form innovations $\mathbf{u}_{N t}$ and $\mathbf{v}_{t}$ are not identified, only the reduced form errors $\mathbf{e}_{N t}$ in the marginal model are identified. ${ }^{2}$

One possibility to study the implications of the high-dimensional VAR model would be to conduct generalized impulse response analysis. However, generalized impulse response functions cannot be given an economic interpretation, and therefore, we focus on structural impulse responses, as opposed to the generalised impulse responses, in our comparison of the pre-crisis, crisis and postcrisis periods.

\subsection{Identification of shocks}

As explained above, our focus is on the transmission of risk shocks and liquidity shocks to global financial markets. In the benchmark specification, risk is proxied through the VIX and liquidity through the US TED spread, as these are the most widely used measures for risk and liquidity

\footnotetext{
${ }^{2}$ See Chudik and Pesaran (2011a) for details.
} 
conditions, both for the US and globally. Moreover, we analyse how asset prices (equity returns and bond yields), exchange rates and capital flows (into bonds and equities) respond to risk and liquidity shocks. We identify the liquidity shock and the risk shock by imposing a priori knowledge on the behavior of selected financial market variables in response to such global shocks. Our identification scheme is in the form of sign restrictions on the impulse responses and combines the schemes used in Chudik and Fratzscher (2011) and Bussiere, Chudik, and Mehl (2011).

An important question is the separation of liquidity shocks and risk shocks. The short-run sign restrictions imposed for identification stem from the literature of time-varying risk of economic disaster and its impact on asset prices and the business cycle (see e.g. Barro (2006), Gabaix (2007), Gourio (2010)). Gourio (2010) shows that disaster risk lowers returns of risky financial assets (e.g. equities) while increasing the price, i.e. reducing the yield of relatively safer financial assets, such as sovereign bonds. Following this argument, we identify shocks to risk as an increase in the VIX coupled with a drop in both US equity returns and US bond yields, and an aprpeciation of save-haven currencies (US dollar, yen and Swiss franc). Importantly, note that no other restrictions are imposed on any of the non-US/foreign variables. By contrast, a shock to liquidity is identified as a rise in the TED spread, together with an increase in US bond yields and a drop in US equity returns. Again, we impose these sign restrictions only on the response of these US variables.

Table 1 summarizes the information used to differentiate the risk and liquidity shocks from other global shocks.

Table 1: Summary of sign restrictions on contemporaneous responses.

\begin{tabular}{|c|c|c|c|c|c|c|c|}
\hline & \multicolumn{5}{|c|}{ US variables } & \multicolumn{2}{|c|}{ " non-US variables } \\
\hline & bonds & stocks & US dollar & $v i x_{t}$ & $t e d_{t}$ & Swiss franc & Japanese yen \\
\hline risk shock & - & - & + & + & . & + & + \\
\hline liquidly shock & + & - & . & . & + & . & . \\
\hline
\end{tabular}

\section{Data}

We now describe the data. Our analysis uses weekly data. Using weekly, rather than lower frequency data has the advantage that it captures better the transmission of shocks in financial markets. 
Moving to higher than weekly frequency is complicated by the non-overlapping trading times across markets, a problem which is reduced by using weekly frequency. Data sample starts in 2005, which allows us to distinguish between a pre-crisis period - 1 January 2005 - 6 August 2007, a crisis period - 7 August 2007 - 10 July 2009, and post-crisis period 17 July 2009 - 13 July 2011.

Overall, we have data on 28 advanced and emerging economies, representing about $86 \%$ of world output (in 2011 and in market prices). In order to detect larger trends and patterns and for better clarity of exposition, we distinguish between groups of countries, in particular between advanced economies (which excludes the US itself) and emerging markets. An alternative aggregation is across regions, distinguishing between Advanced Europe (euro area, Denmark, Norway, Sweden, Switzerland, UK) ${ }^{3}$ and other advanced economies (Japan, New Zealand, Australia), as well as across emerging market regions - Emerging Asia (China, Hong Kong, India, Indonesia, Malaysia, Philippines, Singapore, Taiwan, Thailand), Emerging Europe (Czech Republic, Hungary, Poland, Russia, and also including Turkey and South Africa), and Latin America (Argentina, Brazil, Mexico). Other emerging economies have been excluded because of data issues.

All of the financial market variables we use stem from Bloomberg, Datastream, and Haver Analytics, and have a standard definition. For government bond yields, we use longer maturities (5-10 years, where available). For stock markets, we use MSCI country indices in local currency. We use local currency returns in order to be consistent with the measurement of the government bonds, as well as to avoid that changes in the comovement across equity markets results from changes in exchange rate comovements. Nominal effective exchange rates are BIS broad (58 country) indices with the exception of the euro, which is based on the ECB definition. Table 1 provides a detailed description of the data. Figure A.1 examines comovements in the transformed data - weekly changes in bond yields, weekly returns on stock market indices, and weekly returns on effective exchange rates- using Pesaran's CD test statistics and one year rolling windows. These results shows that (i) the highest co-movement is in stock markets (CD tests are in the range 50-90), followed by bond markets (15-30), while foreign exchange markets commove the least $(-5$ to +15$)$. Noting that this statistics is normally distributed under the null of no cross-section dependence, it is clear that these comovements are quite significant; albeit no clearly interpretable time pattern can be depicted from Figure A.1.

Finally, a fairly novel contribution of the paper is the use of high-frequency data on capital

\footnotetext{
${ }^{3}$ Note that we treat the euro area as a single economy, rather than taking its member states individually.
} 
flows, which stems from the data provider EPFR. ${ }^{4}$ The data covers weekly net flows of portfolio equity and of bonds for a broad set of advanced and emerging markets, and is based on portfolio decisions of abpout 16,000 equity funds and about 8,000 bond funds. Although EPFR capital folow data captures only about 5-20\% of the market capitalization in equity and in bonds for most countries, they have been shown to be strongly correlated with BoP data at lower frequencies. Hence they constitute good proxies for the overall capital flows for equities and for bonds. The data is transformed into a sample that fits the purpose of the analysis for the paper. Specifically, net capital flows are aggregated at the level of each recipient country.

\section{Findings}

This section reports the empirical findings. The benchmark estimates of the high-dimensional VAR models are summarized in Subsection 4.1. The subsequent subsection then presents the findings from the impulse response analysis, while the final subsection reports on the determinants of the differences in the cross-country heterogeneity in the transmission of shocks.

\subsection{Estimation results for High dimensional VAR models}

The estimation results indicate that our high-dimensional VAR models appear to describe the dynamic interactions between markets and countries well. This sub-section reports on a broad range of specification tests.

First, the estimated models are stable. The absolute value of the largest eigenvalue equal 0.59 in pre and post-crisis periods and 0.51 in the crisis period. In all cases it is well below one implying systems are stable. We would expect crisis period to exhibit more persistence compared to the pre and post-crisis periods, due to presumably larger limits to arbitrage during the crisis. Figure A.2 plots the following measure of overall persistence based on estimated eigenvalues,

$$
\mathfrak{p}_{P, s}=\frac{1}{n_{\lambda}} \sum_{j=1}^{n_{\lambda}}\left(\widehat{\lambda}_{P, j}\right)^{s}, \text { for } s=1,2, . .
$$

where $P \in\{$ pre,crisis, post $\}$ is subscript denoting the three estimation periods, $s$ is chosen time

horizon, $\widehat{\lambda}_{P, j}$ is $j$-th estimated eigenvalue and $n_{\lambda}$ is the number of eigenvalues. According to this

\footnotetext{
${ }^{4}$ See Fratzscher (2011) for more details on this data set.
} 
measure, overall persistence is very similar in pre-crisis and post-crisis VARs, and slightly more elevated during the crisis, as expected, but the differences between the crisis and the tranquil periods appear quite small.

Second, many of the estimated coefficients are statistically significant. A summary of significance levels for selected groups of coefficients is reported in Table A.2. It is interesting to see that there are lot of similarities across the three estimation periods. The same market contemporaneous cross-section averages are highly significant in $96 \%$ cases for stock market, and about $67 \%-85 \%$ for foreign exchange and bond markets. Cross-section averages from different markets appear not very important, perhaps with the exception of foreign exchange market during the crisis period (significant in $15 \%$ and $22 \%$ of countries for bonds and stock markets, respectively). Contemporaneous US variables are also very important within a given market segment. The US exchange rate is found to be important also for stock markets in all three periods, and high rejection rates are found for US bond yields in stock and foreign exchange markets regressions in the crisis period as well. The crisis period seems to have slightly higher rejection rates, possibly indicating a stronger degree of cross-section dependence compared to tranquil periods. Contemporaneous values of VIX and TED have rather small rejection rates (4-11\%) with the exception of the TED spread during the crisis (11-26\%). Finally, it is interesting that own lags of bond yields are generally important also for other market segments in all periods. This is not the case for the own lags of stock returns and foreign exchange markets.

Third, the signs and magnitudes of the coefficients are intuitive and economically meaningful. We report a summary of contemporaneous (short-run) elasticities in Table A.3. Contemporaneous elasticities of cross-section averages are in line with those reported in the literature. We find a broadly stable average elasticity for AE stock markets of about 0.71-0.74, while this elasticity is larger than one and broadly stable at about 1.15 in case of emerging economies. The difference between advanced and emerging economies is more stark in case of bonds and foreign exchange markets. Focusing still on the results for cross-section averages, the average elasticity in the case of advanced bond markets is about $0.36-0.66$ and in the case of emerging bond markets it is about 1.12-1.32. The results for the foreign exchange market also suggest that emerging markets are much more responsive to global market movements, with emerging market elasticities reaching 1.21-1.33, whereas this elasticity is only $0.18-0.39$ in the case of advanced economies. An interesting pattern 
emerges when looking at the results in the bottom half of Table A.3, which summarizes our findings for the contemporaneous elasticities of the US variables. The signs of emerging market elasticities are always opposite to the signs of advanced economies elasticities, suggesting quite differentiated effects of the US variables on the rest of the world - a pattern we will investigate in detail below in the next sections. In the case of bond and stock markets, advanced economies elasticities of US variables are positive across all periods, whereas the corresponding emerging economies elasticities are negative.

Fourth, the fit of conditional models is generally high and driven mostly by the contemporaneous cross-section dependence. At the same time, the marginal models have a relatively low fit. Table A.4 reports a summary of adjusted $R^{2}$. Looking at the marginal stock markets models (US \& CS averages), the fit is negligible, between $-4 \%$ to $+3 \%$ in the tranquil periods and slightly larger $6 \%$ $10 \%$ in the crisis periods. Marginal foreign exchange market models have also a low fit in the range $-3 \%$ to $5 \%$ with the exception of the post-crisis period. Two patterns emerge from bottom part of Table A.4. On the one hand, AE bond and stock markets have a higher fit compared to emerging markets in all estimation periods, by a large margin - about 8 to 30 percentage points. Since the fit of the marginal models is driven mainly by contemporaneous cross-section dependence, this suggests that the degree of cross-section dependence in bond and stock markets across advanced economies is higher than in emerging markets, where idiosyncratic shocks are perhaps more important.

Last but not least, the examination of model residuals does not reveal any important irregularities. $^{5}$

\subsection{Impulse response functions and variance decomposition}

We now turn to the benchmark results based on the impulse responses functions discussed in Sections 2 and the corresponding variance decompositions. Figures A.3-A.12 show the effect of risk shocks on the five variables of interest - bond yields, equity returns, exchange rates, bond flows and equity flows - distinguishing between the more tranquil pre-crisis period (January 2005 to 6 August 2007), the 2007-08 global financial crisis (7 August 2007-10 July 2009) and the post-crisis period with the 2010-11 sovereign debt crisis (11 July 2009-13 July 2011). The figures on the left-hand-side provide the country-specific contemporaneous effects, while those on the right show GDP-weighted averages of these responses by region or country group. Figures A.13-A.22 provide corresponding

\footnotetext{
${ }^{5}$ Residual based statistics are not reported due to space considerations.
} 
results for shocks to liquidity.

\section{FIGURES A.3-A.22}

Given the many elements of the estimates, we organise the discussion of the results along three dimensions - a magnification effect analysing the changes in the strength of the transmission across different time periods, a rebalancing effect highlighting differences across countries, and a composition effect focusing on changes in portfolio allocations across asset classes.

\section{Magnification effect}

A first striking empirical finding is the much stronger effect of shocks to liquidity and to risk on virtually all variables - asset prices, exchange rates and capital flows - during the 2007-08 financial crisis. For many of the variables, the effects of risk and liquidity shocks are twice as large in 2007-08 than in other periods, highlighting that not only risk increased and liquidity contracted dramatically during that period, but that the sensitivity of financial markets and investors to a given shock rose substantially.

By contrast, no such systematic increase seems to be present in the 2010-11 sovereign debt crisis. In fact, it is striking that the response of EME bond yields and EME capital flows to risk and liquidity shocks in the 2009-11 period seems to be muted, exhibiting a similar or even weaker response pattern than even during the more tranquil 2005-07 pre-crisis period. The responses of AEs to such shocks is also mostly lower in the 2009-11 period than the 2007-08 crisis, but this reduction is generally much smaller than for EMEs. Hence, overall, a first key result is that the transmission process of liquidity and risk shocks during the sovereign debt crisis is fundamentally different from the 2007-08 financial crisis. Although EMEs are still generally more affected by a given shock in 2009-11, the effects of shocks have become a lot more similar across countries.

\section{Rebalancing effect}

The IRFs show that shocks both to risk and to liquidity generally induce a rebalancing out of EMEs and into AEs, and in particular into the US. Most striking and visible is this finding for the response of equity flows, which in some cases exhibit net inflows to the US and mostly massive outflows out of EMEs in response to shocks. ${ }^{6}$

\footnotetext{
${ }^{6}$ Note that the units shown on the y-axis of the figures for portfolio capital flows refer to flows relative to total assets under management (AUM); hence figures for EMEs are in some cases substantial given the much smaller size of those markets and corresponding AUM.
} 
Consistent with this picture of rebalancing in capital flows is the response of asset prices and exchange rates. Most importantly, a positive shock to risk raises bond yields in EMEs but lowers them in most AEs. What is striking is that the sensitivity of bond yields of AEs to risk shocks is largest not during the 2007-08 crisis - as it is for EME yields - but during the 2010-11 sovereign debt crisis. This increase in sensitivity is most visible for the US, Switzerland, Norway and the UK. ${ }^{7}$

The same opposite signs in the sensitivity to risk and liquidity shocks across countries is observed for exchange rates. Several AE currencies rise in response to shocks to risk and liquidity, while EME currencies depreciate. What appears to be most striking for the response of exchange rates is the high degree of heterogeneity across countries. For AEs, safe-haven currencies such as the US dollar, Japanese yen and Swiss franc appreciate the most, while commodity currencies, such as the Australian dollar and New Zealand dollar exhibit very substantial depreciations. A similar degree of dispersion is found for EMEs: several currencies of Latin American and Emerging European countries depreciate strongly to risk shocks, while those of Asian economies are mostly stable or even appreciate along with the US dollar, underlining the lower flexibility or pegging of those currencies to the US dollar. ${ }^{8}$

Overall, the evidence on the rebalancing effects across countries strongly points towards a flightto-safety phenomenon of investors, where in response to adverse shocks to liquidity and in particular to risk capital is withdrawn from countries and markets that are perceived to be relatively less safe and are repatriated to those that are considered safer. Not only the response in portfolio flows, but also the response of asset prices and the exchange rate is fully consistent with this hypothesis. Importantly, such a flight-to-safety phenomenon appears to be particularly strong during the 201011 sovereign debt crisis for some AEs.

Composition effect

A third dimension is to take an investor perspective and analyse how shocks to risk and liquidity affect the portfolio choice of investors across different asset classes. As discussed in the Introduction, a large literature has analysed to what extent and under what circumstances it is a portfolio

\footnotetext{
${ }^{7}$ The euro area is included as an aggregate, rather than as individual euro area countries, which may mask a lot of heterogeneity across euro area countries. Given that the data for exchange rates and capital flows is for the euro area as a whole, our preferred choice is to analyse the euro area as a whole, rather than individual countries in the euro area.

${ }^{8}$ Note that the use of effective exchange rates makes these differences in cross-country patterns appear smaller. For instance, the effective depreciation of Latin American currencies is likely to be smaller than the bilateral depreciation against the US dollar if currencies of close trading partners move in the same manner.
} 
rebalancing motive or a return chasing motive that drives investment decisions. The correlation pattern across responses of returns on financial asset, on the one hand, and flows, on the other, allow us to gauge which of these motives is dominant and during which periods.

\section{Table A.6}

For this purpose, Table A.6 provide the sign correlations across the responses of the five endogenous variables for different shocks and time periods, with the responses being those shown in Figures A.3-A.22. It is important to recall that for bonds we measure the reaction of yields, rather than of returns, to risk and liquidity shocks. A decline in the yield of a particular bond, for instance, implies a rise in the price and hence a positive return of that bond. For the purpose of the discussion on portfolio choice, we therefore focus here on the return dimension.

The key finding of such an analysis is that a portfolio rebalancing motive appears to dominate for relatively safe financial assets - primarily for bonds in AEs - as the IRFs for these exhibit a negative correlation between returns and flows conditional on shocks to risk. By contrast, there is a mostly positive correlation between returns and flows for relatively more risky assets - portfolio equity assets in AEs and especially EME equities and bonds - a pattern suggesting the dominance of a return chasing motive.

In more detail, for EMEs, Table A.6 and the IRFs in Figures A.3-A.22 show a positive correlation between returns (equity returns, bonds returns and exchange rate changes) and net flows into equities and bonds conditional on liquidity and risk shocks. In other words, investor decisions with regard to EMEs appears to exhibit a strong positive relation between returns and flows, which suggest a return chasing motive being the dominant driver for such investments. In contrast, for investments $\mathrm{AE}$ bond and FX markets, there is a negative relation between returns and net flows conditional on risk shocks.

As a final note, A.23-A.27 show the variance decomposition for risk shocks. The most important point here is that risk shocks explain quite a substantial share of the movements in asset prices, exchange rates and capital flows. There appear to be no systematic differences across country groups or time periods, underlining the points of the previous sub-section that our VAR specification indeed performs well for a broad set of countries and time periods.

FIGUREs A.23-A.27 
In summary, the results reveal some striking changes in the global transmission of risk and liquidity shocks, both over time and across countries. Importantly, the transmission process during the 2010-11 sovereign debt crisis appears to have been fundamentally different from the 2007-08 financial crisis - the shock transmission has become much more similar across countries, with EMEs no longer being most exposed to adverse shocks to global liquidity and risk. Moreover, the transmission pattern we have discovered stresses the importance of a flight-to-safety phenomenon, which has become stronger during the 2010-11 sovereign debt crisis, in particular with a rise in risk driving down bond yields in key AEs.

\subsection{Determinants of cross-country differences in the transmission of shocks}

The previous section has highlighted that there is a substantial degree of heterogeneity across countries in the response patterns to global risk shocks. This section analyses what factors may help explain this cross-country heterogeneity.

To shed light on the cross-section heterogeneity in the transmission of the global shocks to the rest of the world, we estimate the following cross-section regression

$$
y_{i}^{(a)}=c^{(a)}+\sum_{\ell=1}^{K} \beta_{\ell}^{(a)} x_{i \ell}+\zeta_{i}^{(a)}, \text { for } i=2, \ldots, N
$$

where $y_{i}^{(a)}$ is the contemporaneous impact of a global shock $a$ (to risk or liquidity) on the stock market, the foreign exchange market or the money market of country $i$, and $x_{i \ell}$ for $i=1, \ldots, N-1$ and $\ell=1,2, \ldots, K$ is the set of $K$ fundamentals specific to country $i$.

We focus on two alternative explanations for why a country may respond more or less strongly to a given US-specific shock than other countries. A first potential explanation is the direct exposure to the US economy, either through trade or through financial linkages. One would expect that countries with more trade with the US (relative to domestic GDP, or to total trade) or with stronger financial linkages are affected more strongly, as the crisis in the US should set off a decline in US import demand and a repatriation of capital to the US. An alternative explanation is that the global shock transmission may depend on the strength of country-specific fundamentals. This implies that during a crisis, investors may not withdraw capital indiscriminately, but may focus on those with weaker fundamentals and less resilience to external shocks. 
Hence, our set of regressors includes both the country-specific macro variables (such as the current account, reserves, trade openness, financial integration), country-specific institutional variables (the quality of the institutions) and also bilateral trade and financial debt and equity exposures to the United States. A full list is provided in Table 2.

\section{Table 2: List of country fundamentals.}

\begin{tabular}{l}
\hline \hline Macroeconomic \\
\hline Openness, financial integration, rating notches, reserves as a share of GDP \\
unemployment, growth, current account as a share of GDP \\
\hline Quality of institutions \\
\hline ICRG institutional measures: political category index, financial category index, \\
economic category index \\
\hline Bilateral exposure to US \\
\hline trade exposure, financial debt exposure, financial equity exposure \\
\hline \hline
\end{tabular}

We have in total 14 candidate explanatory variables and our country dimension is 28 . Hence, instead of running least squares on the full set of regressors, or a general-to-specific selection procedures to select a parsimonious model, we adopt the Bayesian Averaging of Classical Estimates (BACE) approach, as outlined by Sala-i-Martin et al. (2004), to analyze factors behind the crosscountry heterogeneity of the transmission of US shocks to the rest of the world. The BACE approach was used by Sala-i-Martin et al. (2004) to analyze determinants of growth. It combines the averaging of estimates across models estimated by classical ordinary least squares (OLS) and is particularly useful for understanding which of the large set of determinants (if any) might play a role empirically. We refer reader for the detailed description of BACE approach to Sala-i-Martin et al. (2004).

We run three different BACE estimations, one for each period (the periods before during and after the crisis). Summary of the importance of individual fundamentals in explaining the transmission process is reported in Table A.5. This table reports posterior inclusion probabilities and value larger than $50 \%$ indicates that the fundamental might have played a role in explaining the cross section heterogeneity. Overall, the results provide evidence that real or financial exposure to the US has played a substantial role in explaining the global transmission of the crisis. By contrast, the quality of institutions and domestic fundamentals - such as the size of reserves and the sovereign 
rating - appear to have been relevant as well.

We stress that this evidence is no more than illustrative as our analysis here is conducted purely in the cross-section, and the size of our cross-section is limited to the 28 economies in our sample. Nevertheless, these points help illustrate the heterogeneity and some of the sources of the heterogeneity in the global transmission process.

\section{Conclusions}

The global economy and global capital markets have become increasingly integrated and interdependent over the past decade. The purpose of this paper has been to understand the global transmission process of important shocks during crisis periods - shocks to liquidity and to risk across different financial market segments for a broad set of 28 advanced and emerging economies. The paper has used a relatively novel empirical methodology, building on the growing literature on high-dimensional VARs, which specifically takes into account the rich dimensionality of this multi-country and multi-market setting.

The specific interest of the empirical analysis of the paper has been to understand the changes in the transmission process over time. A key finding highlights the difference between the 200708 financial crisis and the 2010-11 sovereign debt crisis. Shocks during the 2007-08 crisis were transmitted much more strongly and in a much more heterogeneous fashion, with EMEs being affected substantially more strongly than AEs - with both asset returns and capital flow responses being consistent with a clear and persistent flight-to-safety pattern from the former to the latter.

By contrast, the 2010-11 sovereign debt crisis has been different in that a flight-to-safety pattern has been observed across asset classes rather than between EMEs and AEs, with bond markets of a few select AEs experiencing a marked drop in yields in response to risk shocks. In particular, EMEs have been much more resilient and less severely affected by the 2010-11 sovereign debt crisis. Consistent with this pattern, a portfolio choice perspective on investor decisions indicates the presence of a negative conditional correlation pattern between returns and flows for AE bond markets - akin to a portfolio rebalancing motive - whereas investment decisions in EMEs have more generally exhibited a positive conditional correlation with asset returns.

The findings of the paper raise a number of issues. One intriguing, yet open issue is whether the 2010-11 sovereign debt crisis constitutes a structural break for the global transmission process in 
that investments in EMEs are no longer considered the most risky types of investment. Our finding that sovereign ratings explain some of the cross-country differences in the sensitivity to shocks is consistent with the presence of such a structural change - as differences in sovereign risk between AEs and EMEs have indeed become smaller (or in some cases even reversed), adverse shocks to global liquidity and risk may no longer have a larger effect on EMEs.

Another open issue relates to what policy can do to shield the domestic economy and domestic markets from adverse global shocks. The suggestive findings on the determinants of the global shock transmission acknowledge the role of financial exposure and integration of countries as a transmission channel. Yet the findings also underline the importance of sovereign ratings and the quality of domestic institutions as transmission channels, hence factors that are indeed very much the consequence of domestic policy choices. 


\section{References}

Adrian, T. and H. S. Shin (2010). Liquidity and leverage. Journal of Financial Intermediation 19(3).

Barro, R. (2006). Rare disasters and asset markets in the twentieth century. Quarterly Journal of Economics 121, 823-866.

Bekaert, G., M. Ehrmann, M. Fratzscher, and A. Mehl (2011, June). Contagion and the global equity market collapse of the 2007-09 financial crisis. NBER Working Paper No. 17121.

Bekaert, G., C. R. Harvey, and A. Ng (2005). Market integration and contagion. Journal of Business, 39-69.

Bohn, H. and L. Tesar (1996). US equity investment in foreign markets: Portfolio rebalancing or return chasing? American Economic Review 86, 77-81.

Borio, C. (2009). Ten propositions about liquidity crises. BIS Working Paper No. 293, November 2009 .

Branson, W. and D. Henderson (1985). The specification and influence of asset markets. In P. Kenen and R. Jones (Eds.), Handbook of International Economics. North-Holland.

Brennan, M. and H. Cao (1997). International portfolio investment flows. Journal of Finance 52, $1851-1880$.

Brunnermeier, M. and L. H. Pedersen (2009). Market liquidity and funding liquidity. Review of Financial Studies 22(6), 2201-2238.

Bussiere, M., A. Chudik, and A. Mehl (2011). Does the euro make a difference? Spatio-temporal transmission of global shocks to real effective exchange rates in an infinite VAR. ECB Working Paper No. 1292.

Calomiris, C. W. (2008). The subprime turmoil: What's old, what's new and what's next. mimeo, Columbia Business School.

Chudik, A. and M. Fratzscher (2011). Identifying the global transmission of the 2007-09 financial crisis in a GVAR model. European Economic Review 55, 325-339.

Chudik, A. and M. H. Pesaran (2011a). Econometric analysis of high dimensional VARs featuring a dominant unit. forthcomming in Econometric Reviews. 
Chudik, A. and M. H. Pesaran (2011b). Infinite dimensional VARs and factor models. Journal of Econometrics 163, 4-22.

Chudik, A., E. Tosetti, and M. Pesaran (2011). Weak and strong cross section dependence and estimation of large panels. Econometrics Journal 14, C45-C90.

Diebold, F. and K. Yilmaz (2009). Measuring financial asset return and volatility spillovers, with application to global equity markets. Economic Journal 119, 158-171.

Dungey, M. and V. L. Martin (2007). Unravelling financial market linkages during crises. Journal of Applied Econometrics 22(1), 89-119.

Dées, S., F. di Mauro, M. H. Pesaran, and L. V. Smith (2007). Exploring the international linkages of the euro area: a global var analysis. Journal of Applied Econometrics 22, 1-38.

Ehrmann, M. and M. Fratzscher (2005). Equal size, equal role? interest rate interdependence between the euro area and the united states. Economic Journal 115, 930-50.

Ehrmann, M., M. Fratzscher, and R. Rigobon (2010). Stocks, bonds, money markets and exchange rates: Measuring international financial transmission. forthcoming Journal of Applied Econometrics.

Forbes, K. J. and M. Chinn (2004). A decomposition of global linkages in financial markets over time. Review of Economics and Statistics 86, 705-722.

Forbes, K. J. and R. Rigobon (2002). No contagion, only interdependence: Measuring stock market co-movements. The Journal of Finance 57(5), 2223-2261.

Fratzscher, M. (2009). What explains global exchange rate movements during the financial crisis? Journal of International Money and Finance 28, 1390-1407.

Fratzscher, M. (2011). Capital flows, push versus pull factors and the global financial crisis. CEPR Discussion Paper No. 8496.

Gabaix, X. (2007). Variable rare disasters: An exactly solved framework for ten puzzles in macrofinance. Mimeo, NYU.

Gourio, F. (2010). Disaster risk and business cycles. mimeo, Boston University.

Pesaran, M., L. Smith, and R. Smith (2007). What if the UK or Sweden had joined the Euro in 1999? An empirical evaluation using a global VAR. International Journal of Finance and 
Economics 12, 55-87.

Pesaran, M. H. (2006). Estimation and inference in large heterogenous panels with multifactor error structure. Econometrica 74, 967-1012.

Pesaran, M. H., T. Schuermann, and B. J. Treutler (2007). Global business cycles and credit risk. In M. Carey and R. Stultz (Eds.), The risks of financial institutions, Chapter 9. University of Chicago Press.

Pesaran, M. H., T. Schuermann, and S. M. Weiner (2004). Modelling regional interdependencies using a global error-correcting macroeconometric model. Journal of Business and Economics Statistics 22, 129-162.

Sala-i-Martin, X., G. Doppelhofer, and R. I. Miller (2004). Determinants of long-term growth: A bayesian averaging of classical estimates (bace) approach. American Economic Review 94(4), $813-835$.

Taylor, J. B. (2009). The financial crisis and the policy responses: An empirical analysis of what went wrong. NBER Working Paper No. 14631.

Tirole, J. (2010). Illiquidity and all its friends. BIS Working Paper No. 303, 2010.

Tong, H. and S.-J. Wei (2009). Real effects of the subprime mortgage crisis: is it a demand or finance shock? forthcoming in Review of Financial Studies. 


\section{A Tables and Figures}

Table A.1: Data sources

\begin{tabular}{|c|c|c|c|c|}
\hline & \multicolumn{2}{|c|}{ Bonds } & \multirow{2}{*}{$\begin{array}{c}\text { Stocks } \\
\text { Source and } \\
\text { the mnemonic } \\
\end{array}$} & \multirow{2}{*}{$\begin{array}{c}\text { Eff. exchange rates } \\
\text { Source and } \\
\text { the mnemonic } \\
\end{array}$} \\
\hline & Description & $\begin{array}{c}\text { Source and } \\
\text { the mnemonic }\end{array}$ & & \\
\hline Argentina & JPM EMBI global & D: JPMGARG(BYTM) & B: MXAR Index & SDW: BISM.D.QREA.AR.02 \\
\hline Brazil & JPM GBI-EM & D: JGEMBBR(RY) & B: MXBR Index & SDW: BISM.D.QREA.BR.02 \\
\hline China & JPM GBI-EM & D: JGEMBCI(RY) & B: MXCN Index & SDW: BISM.D.QREA.CN.02 \\
\hline Czech Rep. & 10 year gov. bond & $\begin{array}{l}\text { SDW: IRS.D.CZ.L.L40 } \\
\text {.CI.0000.CZK.N.Z }\end{array}$ & B: MXCZ Index & SDW: BISM.D.QREA.CZ.02 \\
\hline Hong Kong & JPM GBI 5-10Y & D: JGHKKK\$(RY) & B: MXHK Index & SDW: BISM.D.QREA.HK.02 \\
\hline Hungary & JPM GBI 5-10Y & D: JGHNKHF(RY) & B: MXHU Index & SDW: BISM.D.QREA.HU.02 \\
\hline India & JPM GBI-EM & D: JGEMBIN(RY) & B: MXIN Index & SDW: BISM.D.QREA.IN.02 \\
\hline Indonesia & JPM GBI-EM & D: JGEMBID(RY) & B: MXID Index & SDW: BISM.D.QREA.ID.02 \\
\hline Malaysia & JPM GBI-EM & D: JGEMBMY(RY) & B: MXMY Index & SDW: BISM.D.QREA.MY.02 \\
\hline Mexico & JPM GBI-EM & D: JGEMBMX(RY) & B: MXMX Index & SDW: BISM.D.QREA.MX.02 \\
\hline Philippines & 10 year gov. bond & H: T566GA@INTDAILY & B: MXPH Index & SDW: BISM.D.QREA.PH.02 \\
\hline Poland & JPM GBI-EM & D: JGEMBPO(RY) & B: MXPL Index & SDW: BISM.D.QREA.PL.02 \\
\hline Russia & JPM GBI-EM & D: JGEMBRS(RY) & B: MXRU Index & SDW: BISM.D.QREA.RU.02 \\
\hline Singapore & JPM GBI All Mat. & D: JGSPAS\$(RY) & B: MXSG Index & SDW: BISM.D.QREA.SG.02 \\
\hline South Africa & JPM GBI 5-10Y & D: JGSAKSR(RY) & B: MXZA Index & SDW: BISM.D.QREA.ZA.02 \\
\hline Taiwan & 2 year gov. bond & B: GVTW2YR Index & B: MXTW Index & SDW: BISM.D.QREA.TW.02 \\
\hline Thailand & JPM GBI-EM & D: JGEMBTH(RY) & B: MXTH Index & SDW: BISM.D.QREA.TH.02 \\
\hline Turkey & JPM GBI-EM & D: JGEMBTK(RY) & B: MXTR Index & SDW: BISM.D.QREA.TR.02 \\
\hline Australia & JPM GBI 5-10Y & D: JGAUKA $\$(R Y)$ & B: MXAU Index & SDW: BISM.D.QREA.AU.02 \\
\hline Denmark & JPM GBI 5-10Y & D: JGDKKDK(RY) & B: MXDK Index & SDW: BISM.D.QREA.DK.02 \\
\hline Euro Area & 3 year gov. bond & B: GECU3YR Index & B: MXEU Index & SDW: EXR.D.Z64.EUR.EN00.A \\
\hline Japan & 10 year gov. bond & B: GJGB10 Index & B: MXJP Index & SDW: BISM.D.QREA.JP.02 \\
\hline New Zealand & JPM GBI 5-10Y & D: JGNZKZ\$(RY) & B: MXNZ Index & SDW: BISM.D.QREA.NZ.02 \\
\hline Norway & 10 year gov. bond & B: GNOR10Y Index & B: MXNO Index & SDW: BISM.D.QREA.NO.02 \\
\hline Sweden & JPM GBI 5-10Y & D: JGSDKSK(RY) & B: MXSE Index & SDW: BISM.D.QREA.SE.02 \\
\hline Switzerland & 10 year gov. bond & B: GSWISS10 Index & B: MXCH Index & SDW: BISM.D.QREA.CH.02 \\
\hline UK & JPM GBI 5-10Y & D: JGUKKU£(RY) & B: MXGB Index & SDW: BISM.D.QREA.GB.02 \\
\hline US & JPM GBI 5-10Y & D: JGUSKU\$(RY) & B: MXUS Index & SDW: BISM.D.QREA.US.02 \\
\hline Sources: & \multicolumn{4}{|c|}{$\begin{array}{l}\text { All stock market indices are MSCI indices. Effective exchange rates are BIS } 58 \text { currency } \\
\text { indices, with the exception of Euro, which is taken from ECB (EER-20 currency index). }\end{array}$} \\
\hline
\end{tabular}


Table A.2: Significance of estimated coefficients

\begin{tabular}{|c|c|c|c|c|c|c|c|c|c|c|c|c|}
\hline & \multicolumn{4}{|c|}{ Pre-crisis period } & \multicolumn{4}{|c|}{ Crisis period } & \multicolumn{4}{|c|}{ Post-crisis period } \\
\hline & \multicolumn{3}{|c|}{ markets } & \multirow[b]{2}{*}{ all } & \multicolumn{3}{|c|}{ markets } & \multirow[b]{2}{*}{ all } & \multicolumn{3}{|c|}{ markets } & \multirow[b]{2}{*}{ all } \\
\hline & bonds & stocks & FX & & bonds & stocks & FX & & bonds & stocks & FX & \\
\hline \multicolumn{13}{|c|}{ Contemporaneous cross section averages: } \\
\hline bonds & $67 \%$ & $7 \%$ & $0 \%$ & $25 \%$ & $85 \%$ & $7 \%$ & $4 \%$ & $32 \%$ & $81 \%$ & $0 \%$ & $15 \%$ & $32 \%$ \\
\hline stocks & $4 \%$ & $96 \%$ & $11 \%$ & $37 \%$ & $11 \%$ & $96 \%$ & $7 \%$ & $38 \%$ & $7 \%$ & $96 \%$ & $7 \%$ & $37 \%$ \\
\hline FX & $7 \%$ & $7 \%$ & $70 \%$ & $28 \%$ & $22 \%$ & $15 \%$ & $70 \%$ & $36 \%$ & $7 \%$ & $11 \%$ & $70 \%$ & $30 \%$ \\
\hline \multicolumn{13}{|c|}{ Contemporaneous US variables (dominant markets): } \\
\hline bonds & $52 \%$ & $0 \%$ & $0 \%$ & $17 \%$ & $52 \%$ & $30 \%$ & $26 \%$ & $36 \%$ & $37 \%$ & $4 \%$ & $19 \%$ & $20 \%$ \\
\hline stocks & $4 \%$ & $11 \%$ & $4 \%$ & $6 \%$ & $15 \%$ & $41 \%$ & $7 \%$ & $21 \%$ & $7 \%$ & $52 \%$ & $4 \%$ & $21 \%$ \\
\hline $\mathrm{FX}$ & $11 \%$ & $26 \%$ & $93 \%$ & $43 \%$ & $15 \%$ & $37 \%$ & $85 \%$ & $46 \%$ & $0 \%$ & $22 \%$ & $70 \%$ & $31 \%$ \\
\hline VIX & $4 \%$ & $11 \%$ & $7 \%$ & $7 \%$ & $11 \%$ & $11 \%$ & $0 \%$ & $7 \%$ & $11 \%$ & $4 \%$ & $4 \%$ & $6 \%$ \\
\hline TED & $11 \%$ & $4 \%$ & $15 \%$ & $10 \%$ & $11 \%$ & $26 \%$ & $15 \%$ & $17 \%$ & $11 \%$ & $7 \%$ & $11 \%$ & $10 \%$ \\
\hline \multicolumn{13}{|c|}{ Own lags: } \\
\hline bonds & $21 \%$ & $29 \%$ & $43 \%$ & $31 \%$ & $21 \%$ & $18 \%$ & $36 \%$ & $25 \%$ & $29 \%$ & $36 \%$ & $21 \%$ & $29 \%$ \\
\hline stocks & $18 \%$ & $14 \%$ & $4 \%$ & $12 \%$ & $18 \%$ & $57 \%$ & $14 \%$ & $30 \%$ & $0 \%$ & $14 \%$ & $7 \%$ & $7 \%$ \\
\hline $\mathrm{FX}$ & $11 \%$ & $4 \%$ & $18 \%$ & $11 \%$ & $4 \%$ & $18 \%$ & $21 \%$ & $14 \%$ & $7 \%$ & $14 \%$ & $14 \%$ & $12 \%$ \\
\hline
\end{tabular}

Note: This table reports share of significant coefficients at the $5 \%$ nominal size of tests. Entries lower than $5 \%$ are highlited by gray color.

Table A.3: Contemporaneous elasticities.

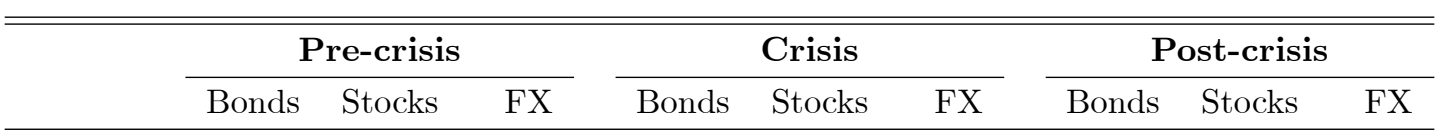

Average elasticity of cross section averages on their domestic counterparts

$\begin{array}{llllllllll}\text { advanced } & 0.47 & 0.71 & 0.18 & 0.36 & 0.74 & 0.32 & 0.66 & 0.74 & 0.39\end{array}$

$\begin{array}{llllllllll}\text { emerging } & 1.22 & 1.17 & 1.33 & 1.32 & 1.15 & 1.21 & 1.12 & 1.16 & 1.24\end{array}$

Average elasticity of US variables on their counterparts in other economies

\begin{tabular}{lrrrrrrrrr} 
advanced & 0.36 & 0.05 & -0.58 & 0.33 & 0.26 & -0.38 & 0.22 & 0.35 & -0.47 \\
emerging & -0.23 & -0.04 & 0.32 & -0.19 & -0.10 & 0.21 & -0.11 & -0.15 & 0.27 \\
\hline \hline
\end{tabular}

Please see notes to Table A.4 for the list of advanced and emerging economies. 
Table A.4: Adjusted $R^{2}$ measures of model fit.

\begin{tabular}{|c|c|c|c|c|c|c|c|c|c|c|c|c|}
\hline & \multicolumn{4}{|c|}{ Pre-crisis } & \multicolumn{4}{|c|}{ Crisis } & \multicolumn{4}{|c|}{ Post-crisis } \\
\hline & \multicolumn{3}{|c|}{ Market } & \multirow[b]{2}{*}{ ave } & \multicolumn{3}{|c|}{ Market } & \multirow[b]{2}{*}{ ave } & \multicolumn{3}{|c|}{ Market } & \multirow[b]{2}{*}{ ave } \\
\hline & bonds & stocks & $\mathrm{FX}$ & & bonds & stocks & $\mathrm{FX}$ & & bonds & stocks & $\mathrm{FX}$ & \\
\hline \multicolumn{13}{|c|}{ Marginal models: } \\
\hline US & $8 \%$ & $2 \%$ & $-1 \%$ & $3 \%$ & $16 \%$ & $6 \%$ & $5 \%$ & $9 \%$ & $31 \%$ & $-1 \%$ & $3 \%$ & $11 \%$ \\
\hline CS averages & $27 \%$ & $-4 \%$ & $-3 \%$ & $7 \%$ & $25 \%$ & $10 \%$ & $2 \%$ & $12 \%$ & $11 \%$ & $3 \%$ & $16 \%$ & $10 \%$ \\
\hline \multicolumn{13}{|c|}{ Conditional models: } \\
\hline advanced & $54 \%$ & $58 \%$ & $37 \%$ & $49 \%$ & $51 \%$ & $77 \%$ & $47 \%$ & $58 \%$ & $53 \%$ & $69 \%$ & $44 \%$ & $55 \%$ \\
\hline emerging & $27 \%$ & $49 \%$ & $42 \%$ & $39 \%$ & $43 \%$ & $69 \%$ & $48 \%$ & $53 \%$ & $33 \%$ & $55 \%$ & $48 \%$ & $45 \%$ \\
\hline
\end{tabular}

Notes: Group of advanced countries excludes the US and consists of Australia, Denmark, Euro Area, Japan, New Zealand, Norway, Sweden, Switzerland and UK. Group of emerging economies consists of Argentina, Brazil, China, Hong Kong, Hungary, India, Indonesia, Malaysia, Mexico, Poland, Russia, Singapore, South Africa, Taiwan, and Turkey. Average fit is reported for each group of countries.

Table A.5: Importance of country fundamentals in explaining the transmission of shocks: Posterior inclusion probabilities.

\begin{tabular}{|c|c|c|c|c|c|c|c|}
\hline \multirow[b]{2}{*}{ Fundamental: } & \multicolumn{4}{|c|}{ Number of times with larger p-value than $50 \%$} & \multicolumn{3}{|c|}{ The largest p-values } \\
\hline & before & during & after & sum & before & during & after \\
\hline Openess & 0 & 0 & 1 & 1 & 0.32 & 0.31 & 0.69 \\
\hline Financial Integration & 0 & 0 & 0 & 0 & 0.29 & 0.25 & 0.43 \\
\hline Trade exposure & 0 & 1 & 3 & 4 & 0.37 & 0.56 & 0.64 \\
\hline Financial equity exposure & 2 & 3 & 1 & 6 & 0.72 & 0.91 & 0.57 \\
\hline Financial debt exposure & 0 & 1 & 0 & 1 & 0.40 & 0.67 & 0.37 \\
\hline Rating notches & 3 & 1 & 3 & 7 & 0.91 & 0.96 & 0.99 \\
\hline ICRG: political & 0 & 1 & 1 & 2 & 0.47 & 0.55 & 0.71 \\
\hline ICRG: financial & 2 & 1 & 1 & 4 & 1.00 & 0.96 & 0.91 \\
\hline ICRG: economic & 0 & 0 & 0 & 0 & 0.29 & 0.25 & 0.26 \\
\hline Market capitalization & 1 & 0 & 0 & 1 & 0.69 & 0.45 & 0.47 \\
\hline Reserves & 1 & 0 & 0 & 1 & 0.63 & 0.24 & 0.45 \\
\hline Unemployment & 2 & 0 & 0 & 2 & 0.84 & 0.49 & 0.38 \\
\hline Economic growth & 0 & 0 & 0 & 0 & 0.45 & 0.26 & 0.39 \\
\hline Current account & 0 & 0 & 0 & 0 & 0.28 & 0.31 & 0.29 \\
\hline
\end{tabular}


Table A.6: Sign correlations matrix of the shock responses across all countries.

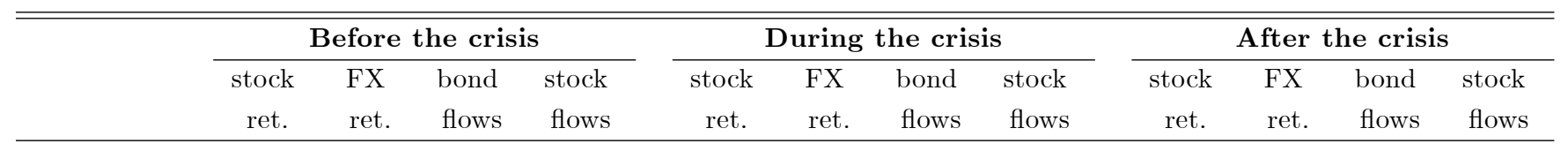

\begin{tabular}{|c|c|c|c|c|c|c|c|c|c|c|c|c|}
\hline \multirow[b]{2}{*}{ bond yields } & \multicolumn{12}{|c|}{ Risk shock } \\
\hline & 0.21 & -0.43 & -0.18 & 0.14 & 0.21 & -0.14 & 0.18 & 0.21 & 0.14 & -0.14 & -0.07 & 0.07 \\
\hline stock returns & 1 & 0.07 & 0.54 & 0.93 & 1 & 0.50 & 0.96 & 1.00 & 1 & 0.43 & 0.71 & 0.93 \\
\hline FX returns & & 1 & 0.18 & 0.14 & & 1 & 0.46 & 0.50 & & 1 & 0.43 & 0.36 \\
\hline \multirow[t]{2}{*}{ bond flows } & & & 1 & 0.68 & & & 1 & 1.42 & & & 1 & 0.95 \\
\hline & \multicolumn{12}{|c|}{ Liquidity shock } \\
\hline bond yields & -0.36 & -0.14 & -0.04 & -0.29 & -0.07 & -0.21 & -0.04 & 0.00 & -0.79 & -0.29 & -0.07 & -0.71 \\
\hline stock returns & 1 & 0.21 & 0.25 & 0.79 & 1 & -0.14 & 0.68 & 0.64 & 1 & 0.21 & 0.14 & 0.79 \\
\hline FX returns & & 1 & 0.25 & 0.14 & & 1 & -0.11 & -0.07 & & 1 & 0.29 & 0.14 \\
\hline bond flows & & & 1 & 0.37 & & & 1 & 1.11 & & & 1 & 0.11 \\
\hline
\end{tabular}

\begin{tabular}{|c|c|c|c|c|c|c|c|c|c|c|c|c|}
\hline \multirow[b]{2}{*}{ bond yields } & \multicolumn{12}{|c|}{ Risk shock } \\
\hline & 0.36 & -0.21 & n.a. & 0.29 & 0.36 & 0.07 & 0.36 & 0.36 & 0.36 & 0.07 & 0.32 & 0.29 \\
\hline stock returns & 1 & -0.21 & n.a. & 0.29 & 1 & 0.07 & 0.36 & 0.36 & 1 & 0.07 & 0.32 & 0.29 \\
\hline FX returns & & 1 & n.a. & -0.14 & & 1 & 0.07 & 0.07 & & 1 & 0.04 & 0.00 \\
\hline \multirow[t]{2}{*}{ bond flows } & & & 1 & -0.11 & & & 1 & 0.53 & & & 1 & 0.37 \\
\hline & \multicolumn{12}{|c|}{ Liquidity shock } \\
\hline bond yields & 0.00 & 0.14 & n.a. & 0.00 & 0.07 & -0.07 & 0.07 & 0.07 & -0.21 & -0.07 & -0.18 & -0.21 \\
\hline stock returns & 1 & 0.07 & n.a. & 0.21 & 1 & -0.07 & 0.36 & 0.21 & 1 & 0.07 & 0.32 & 0.21 \\
\hline FX returns & & 1 & n.a. & 0.07 & & 1 & -0.07 & 0.07 & & 1 & 0.04 & 0.07 \\
\hline bond flows & & & 1 & 0.00 & & & 1 & 0.32 & & & 1 & 0.26 \\
\hline
\end{tabular}

Emerging economies

\begin{tabular}{|c|c|c|c|c|c|c|c|c|c|c|c|c|}
\hline \multirow[b]{2}{*}{ bond yields } & \multicolumn{12}{|c|}{ Risk shock } \\
\hline & -0.14 & -0.21 & -0.18 & -0.14 & -0.14 & -0.21 & -0.18 & -0.14 & -0.21 & -0.21 & -0.39 & -0.21 \\
\hline stock returns & 1 & 0.29 & 0.54 & 0.64 & 1 & 0.43 & 0.61 & 0.64 & 1 & 0.36 & 0.39 & 0.64 \\
\hline FX returns & & 1 & 0.18 & 0.29 & & 1 & 0.39 & 0.43 & & 1 & 0.39 & 0.36 \\
\hline \multirow[t]{2}{*}{ bond flows } & & & 1 & 0.79 & & & 1 & 0.89 & & & 1 & 0.58 \\
\hline & \multicolumn{12}{|c|}{ Liquidity shock } \\
\hline bond yields & -0.36 & -0.29 & -0.04 & -0.29 & -0.14 & -0.14 & -0.11 & -0.07 & -0.57 & -0.21 & 0.11 & -0.50 \\
\hline stock returns & 1 & 0.14 & 0.18 & 0.57 & 1 & -0.07 & 0.32 & 0.43 & 1 & 0.14 & -0.18 & 0.57 \\
\hline FX returns & & 1 & 0.25 & 0.07 & & 1 & -0.04 & -0.14 & & 1 & 0.25 & 0.07 \\
\hline bond flows & & & 1 & 0.37 & & & 1 & 0.79 & & & 1 & -0.16 \\
\hline
\end{tabular}

Notes: Sign correlation is computed as a simple correlation coefficient of the signs (i.e. $+1,0$ or -1 ) of the corresponding impulse response impacts on different variables. Results for the bond flows prior the crisis are not reported because only 2 advanced economies have the corresponding data available. 


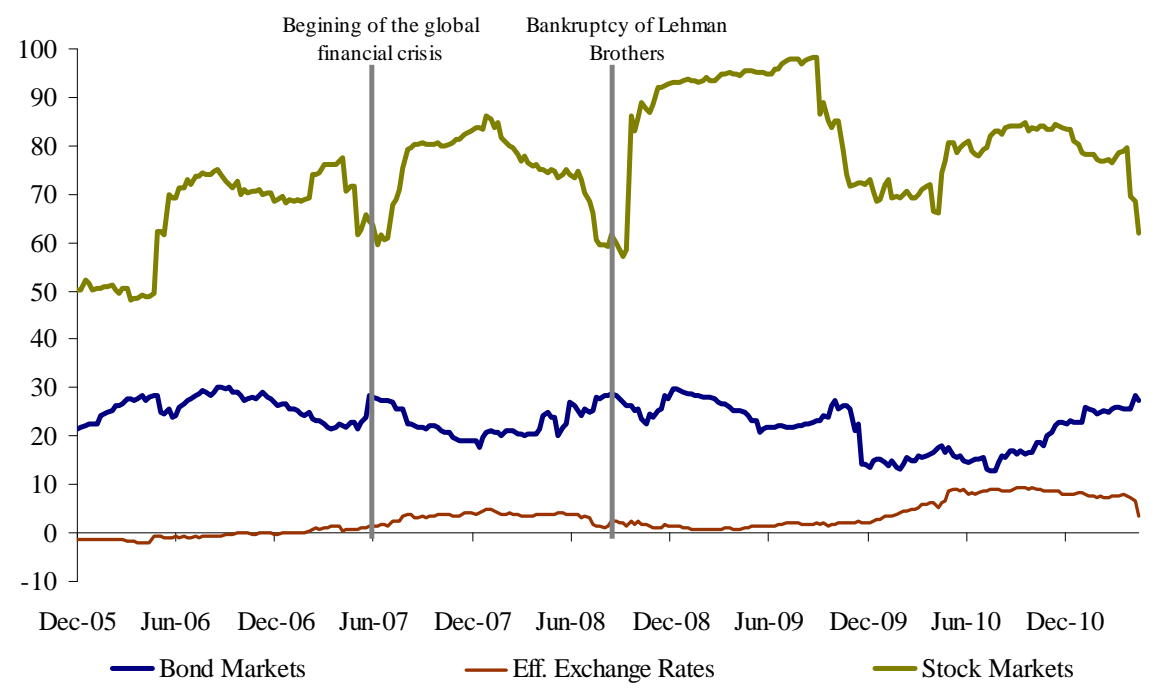

Figure A.1: Pesaran's CD test statistics using one year rolling windows.

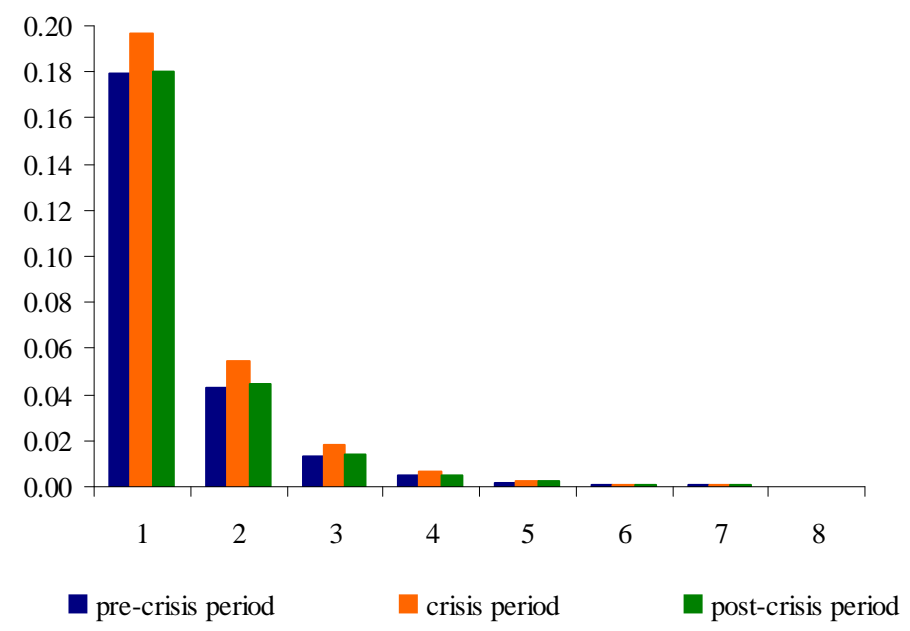

Figure A.2: A measure of overall persistence $\mathfrak{p}_{P, s}$, defined by (6) 


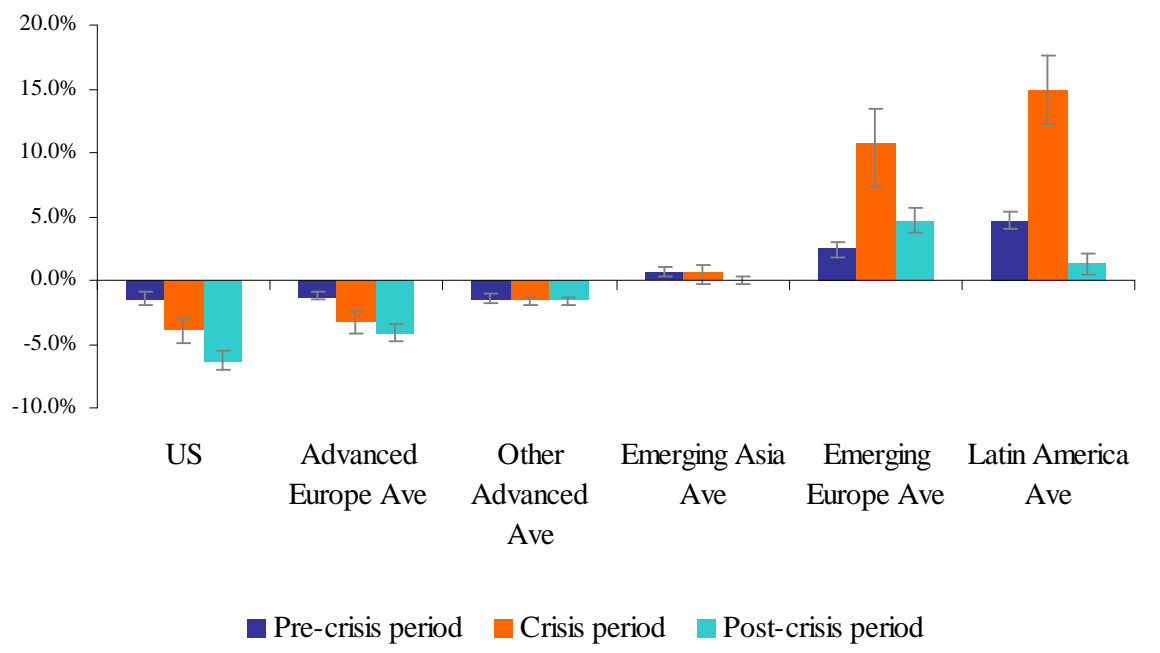

Figure A.3: Contemporaneous impact of one unit risk shock on bond markets in different regions with $25 \%-75 \%$ bootstrap bounds.

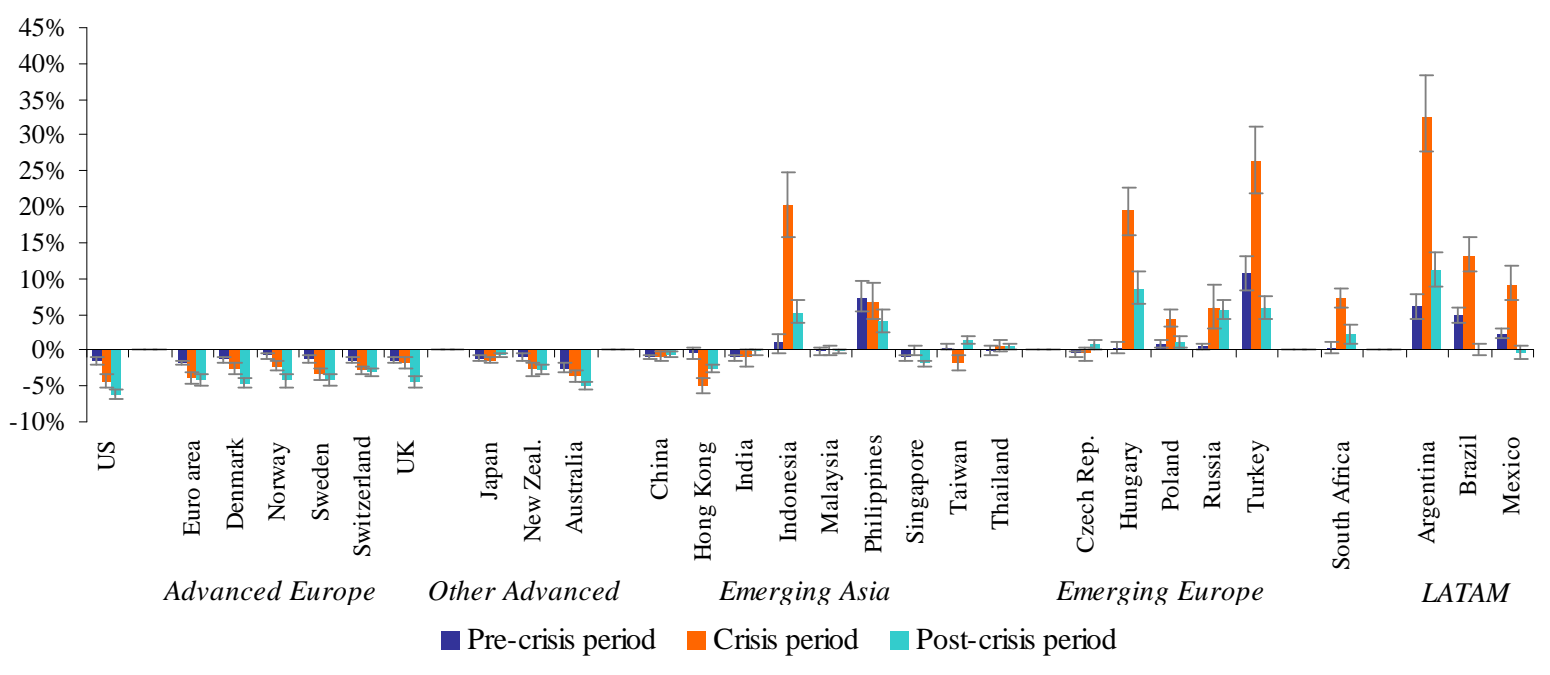

Figure A.4: Contemporaneous impact of one unit risk shock on bond markets in different countries with $25 \%-75 \%$ bootstrap bounds. 


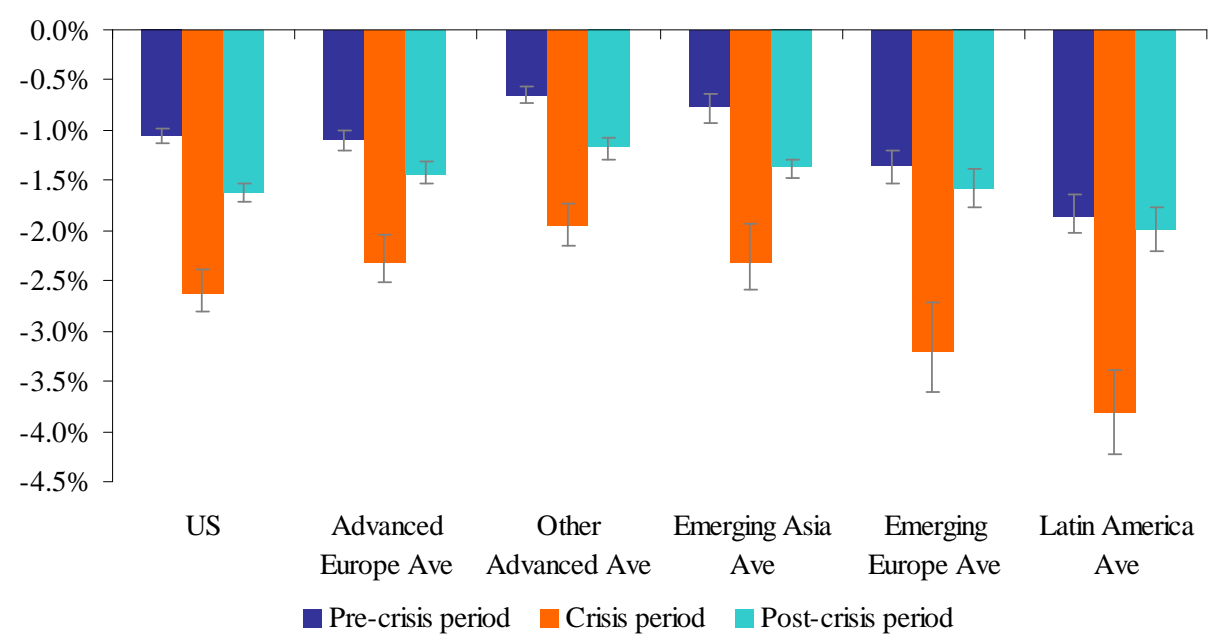

Figure A.5: Contemporaneous impact of one unit risk shock on equity markets in different regions with $25 \%-75 \%$ bootstrap bounds.

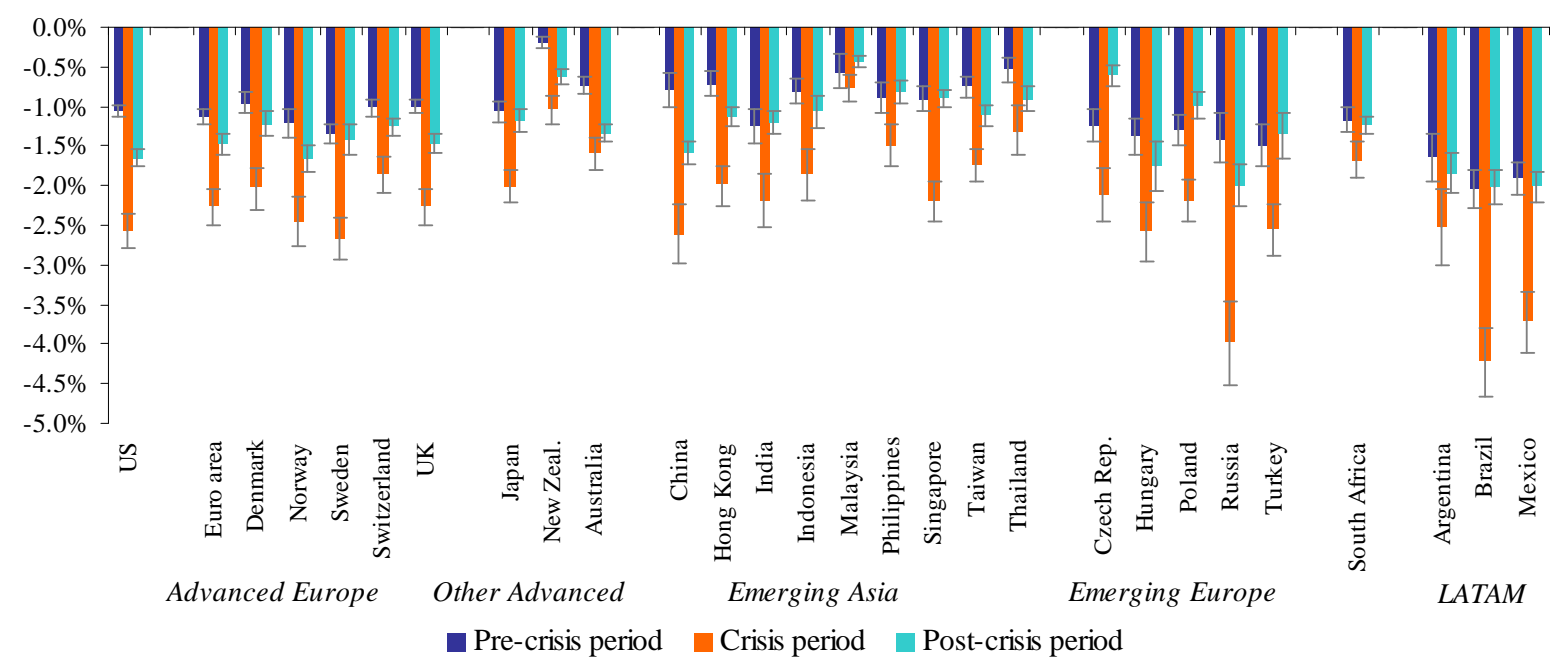

Figure A.6: Contemporaneous impact of one unit risk shock on equity markets in different countries with $25 \%-75 \%$ bootstrap bounds. 


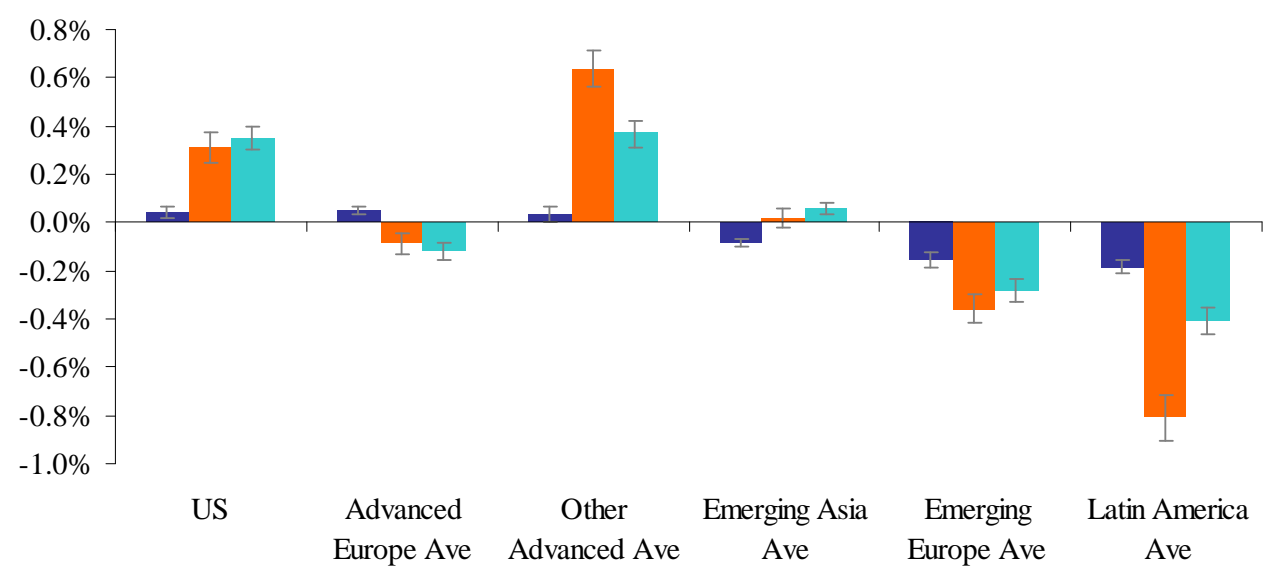

$\square$ Pre-crisis period $\square$ Crisis period $\square$ Post-crisis period

Figure A.7: Contemporaneous impact of one unit risk shock on foreign exchange markets in different regions with $25 \%-75 \%$ bootstrap bounds.

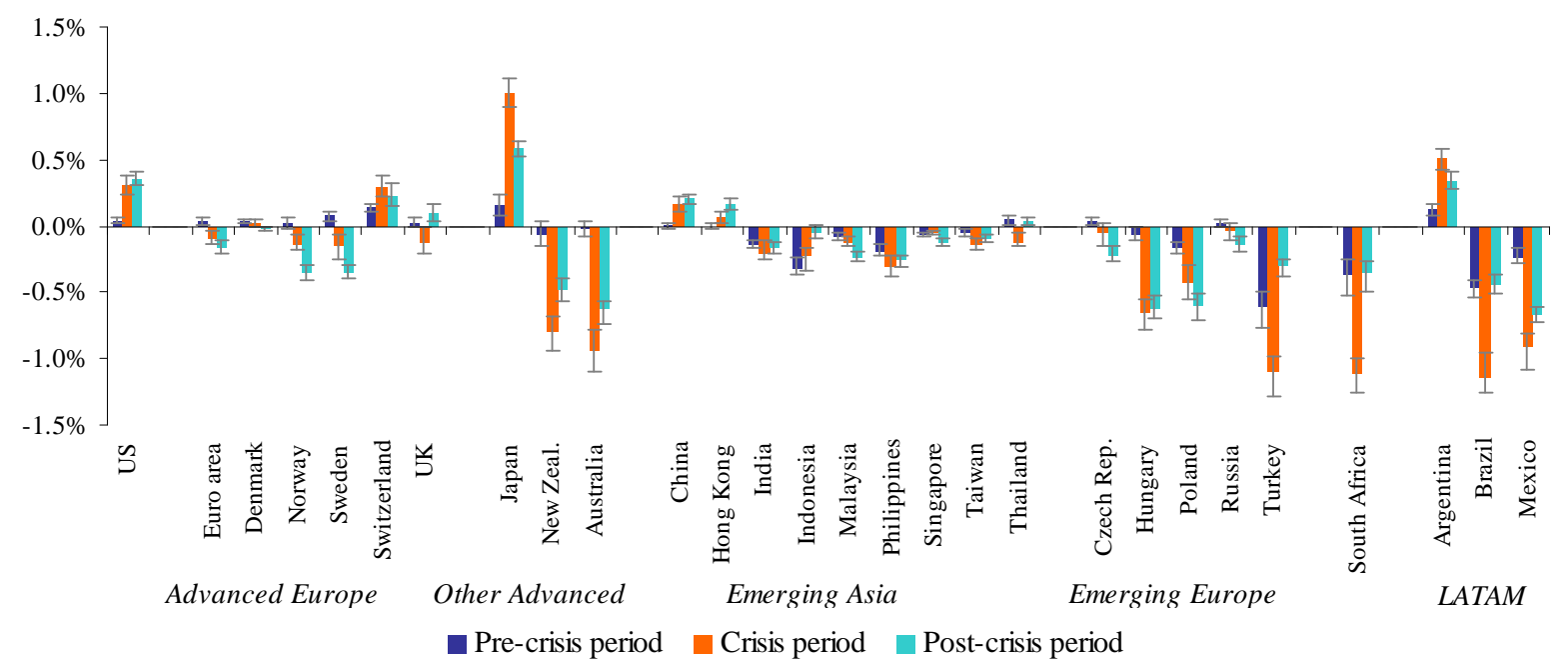

Figure A.8: Contemporaneous impact of one unit risk shock on foreign exchange markets in different countries with $25 \%-75 \%$ bootstrap bounds. 


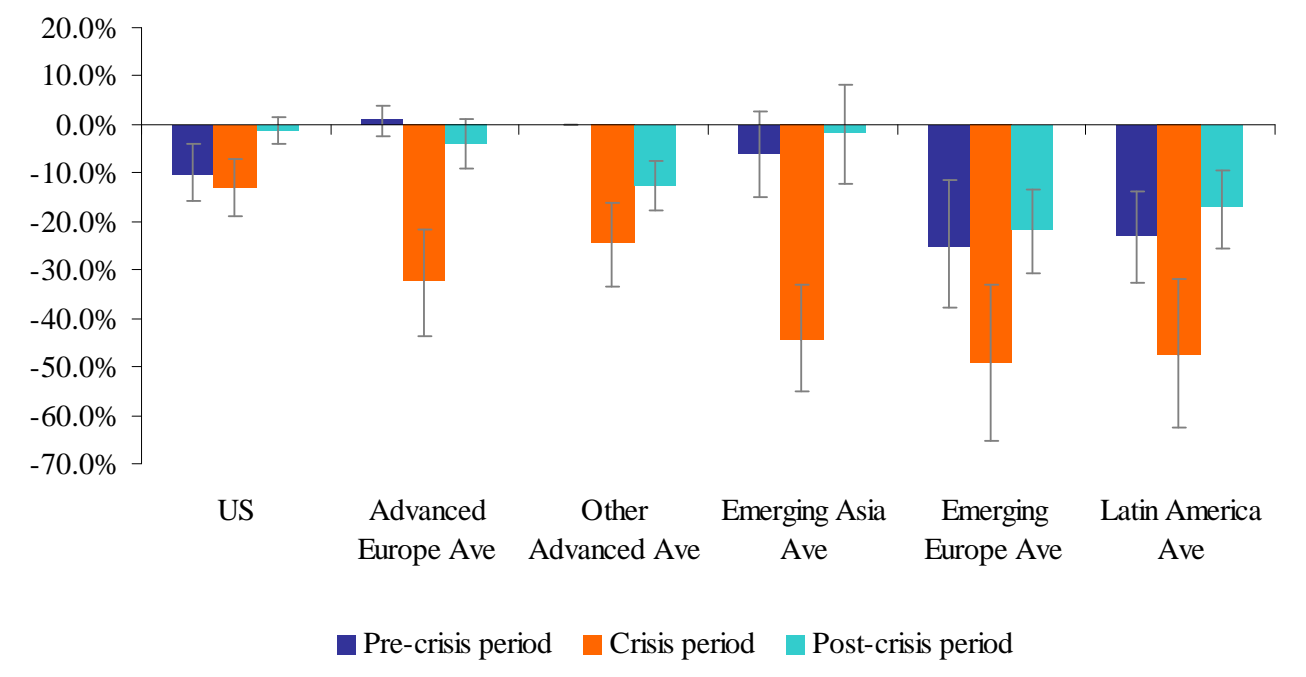

Figure A.9: Cumulative impact of one unti risk shock on bond flows after 4 weeks in different regions with $25 \%-75 \%$ bootstrap bounds.

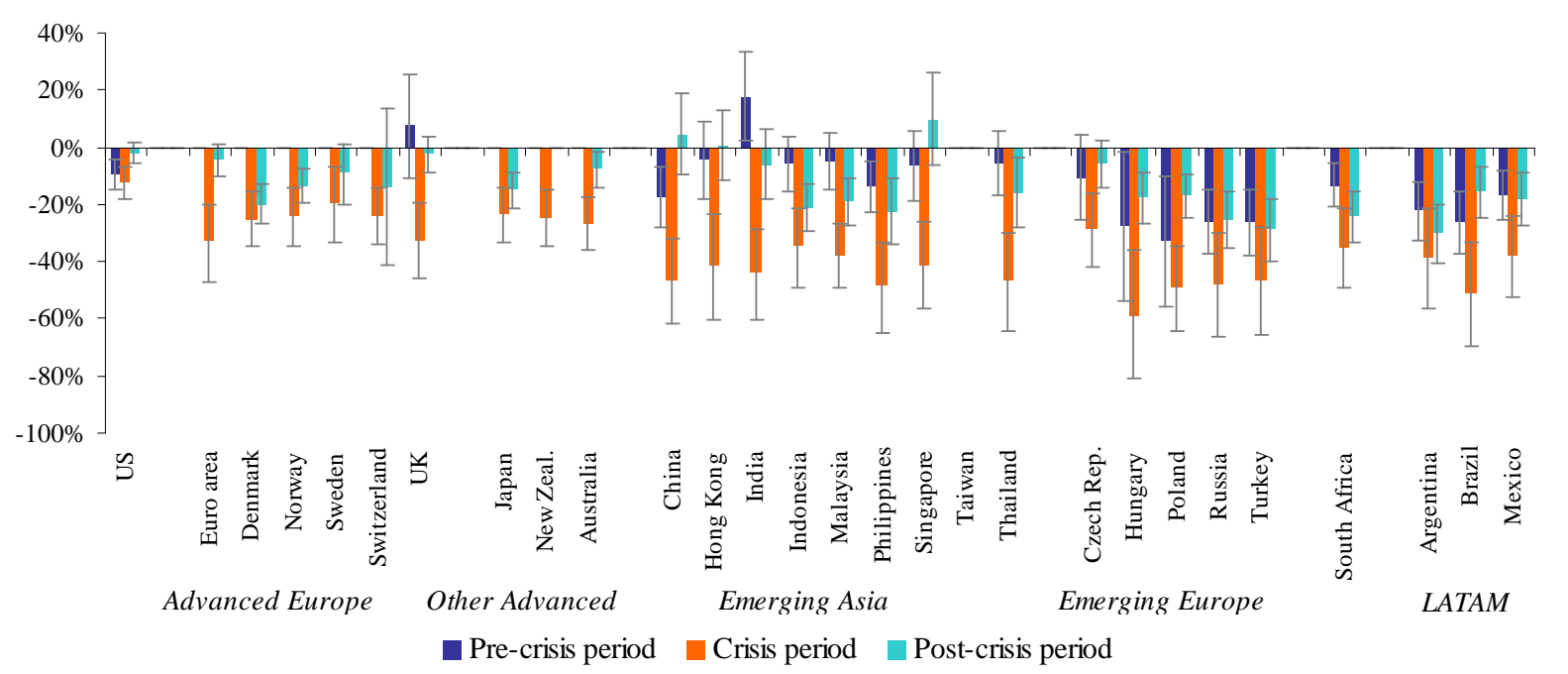

Figure A.10: Cumulative impact of one unit risk shock on bond flows after 4 weeks in different countries with $25 \%-75 \%$ bootstrap bounds. 


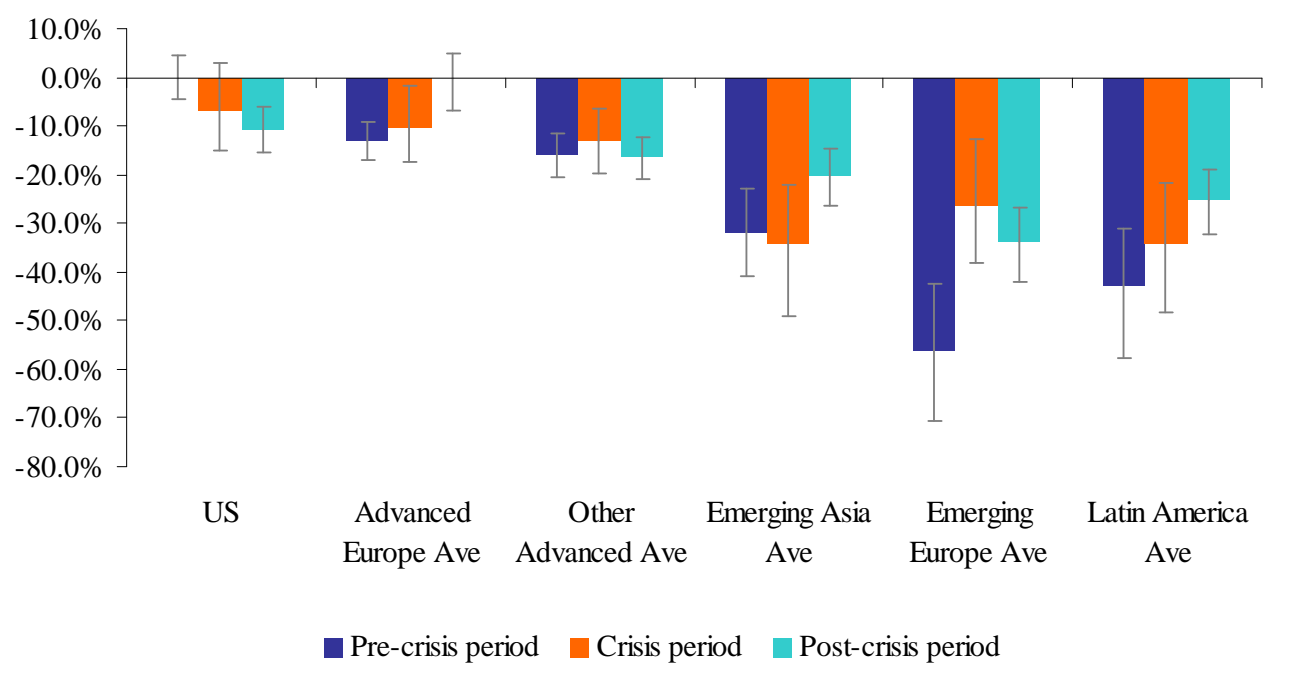

Figure A.11: Cumulative impact of one unit risk shock on equity flows after 4 weeks in different regions with $25 \%-75 \%$ bootstrap bounds.

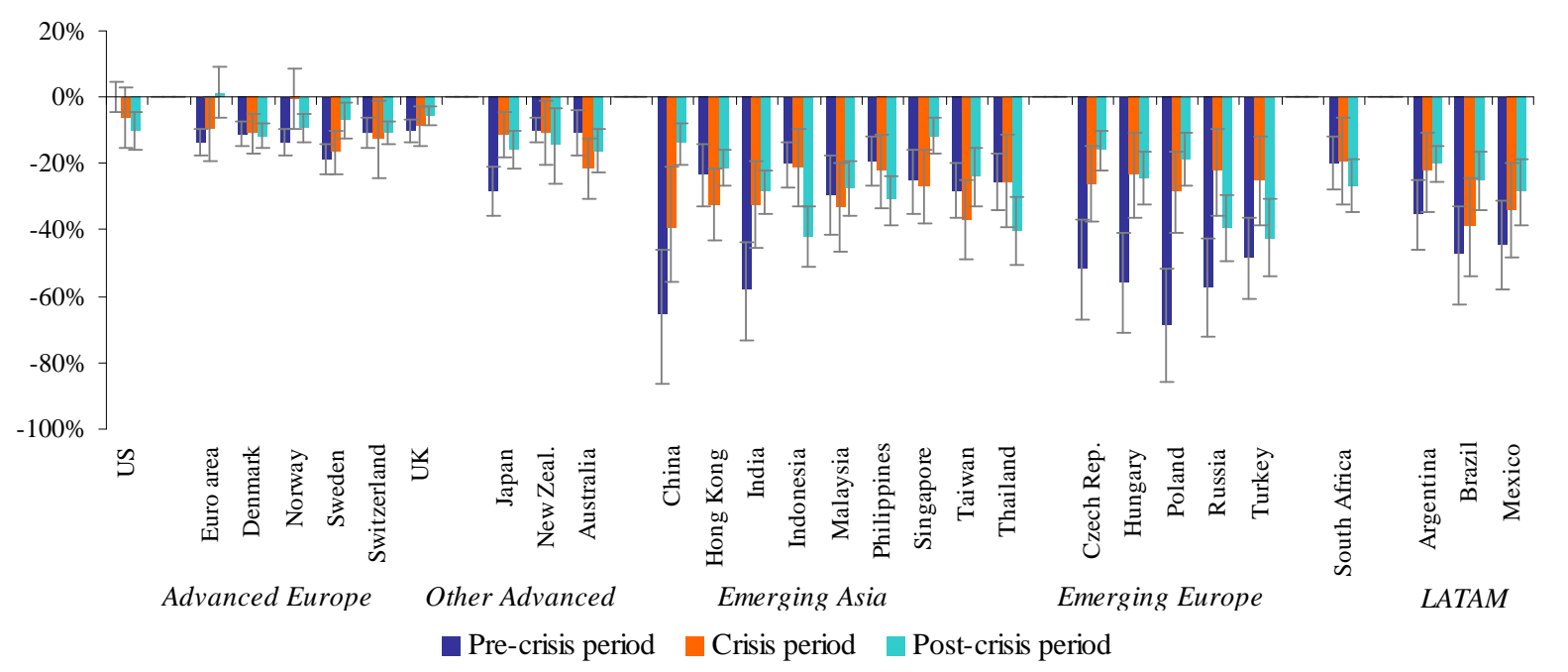

Figure A.12: Cumulative impact of one unit risk shock on equity flows after 4 weeks in different countries with $25 \%-75 \%$ bootstrap bounds. 


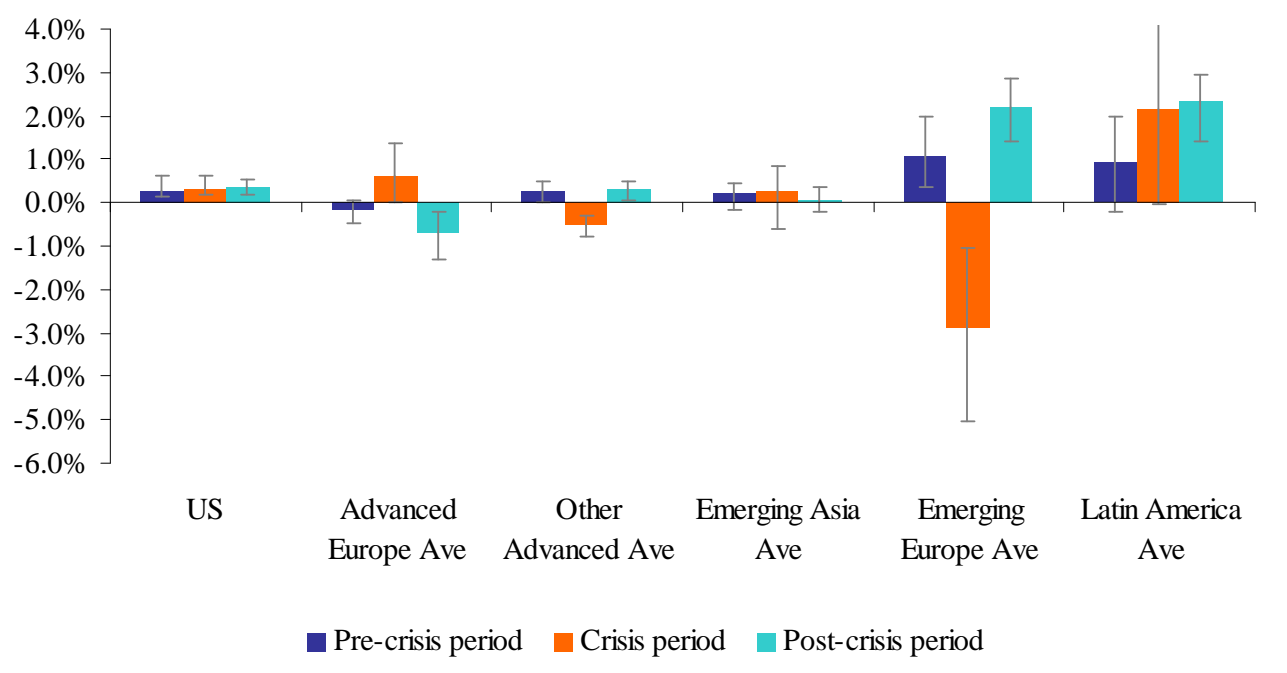

Figure A.13: Contemporaneous impact of one unit liquidity shock on bond markets in different regions with $25 \%-75 \%$ bootstrap bounds.

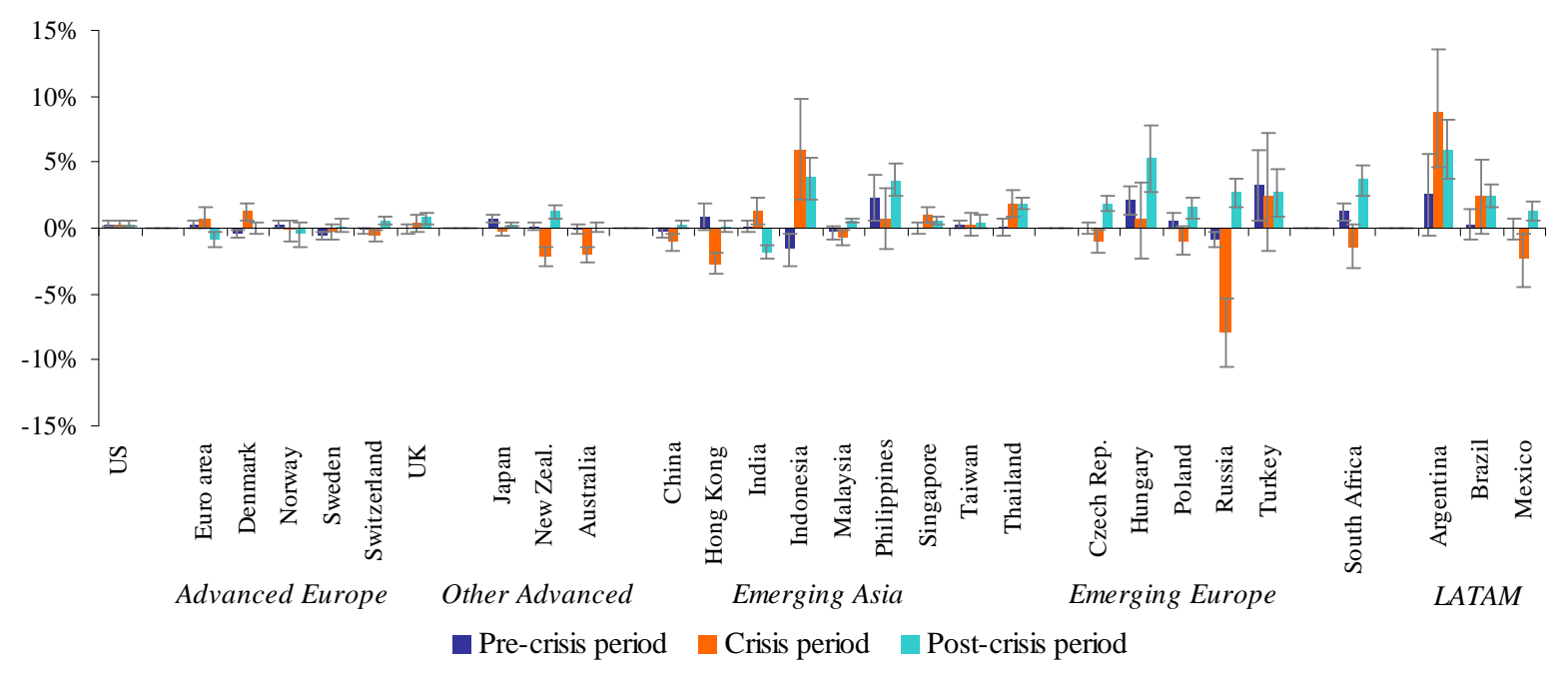

Figure A.14: Contemporaneous impact of one unit liquidity shock on bond markets in different countries with $25 \%-75 \%$ bootstrap bounds. 


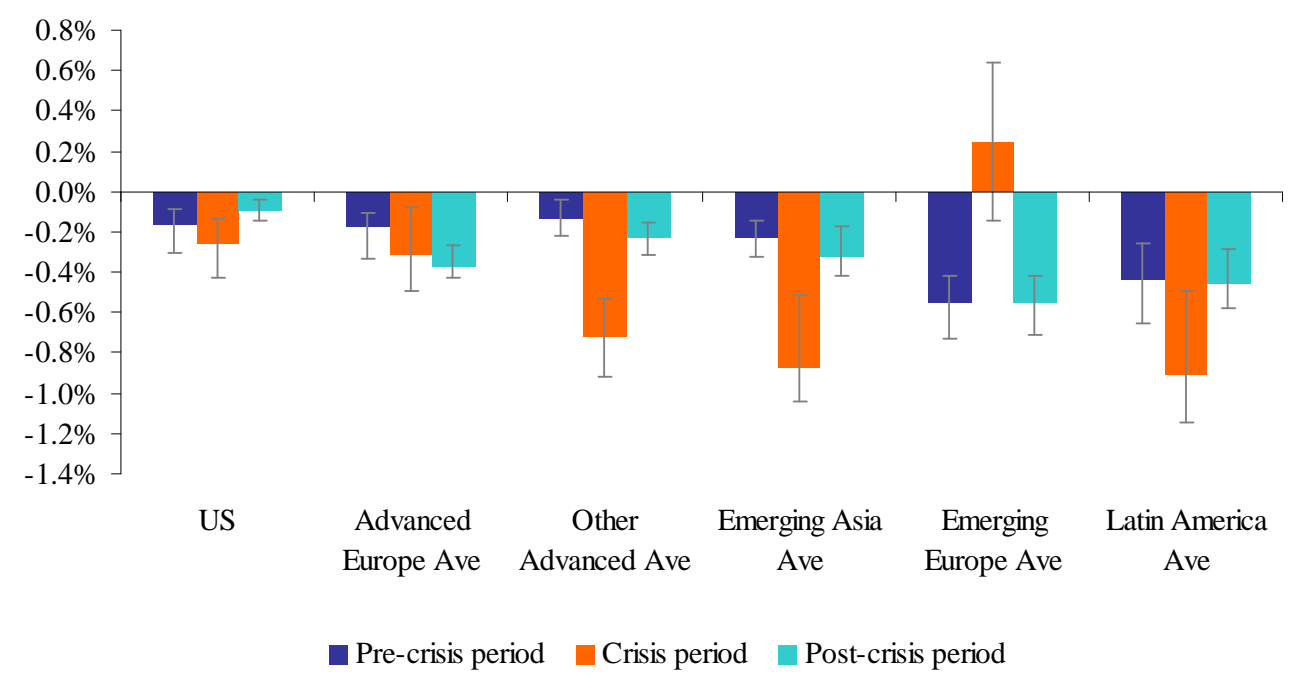

Figure A.15: Contemporaneous impact of one unit liquidity shock on equity markets in different regions with $25 \%-75 \%$ bootstrap bounds.

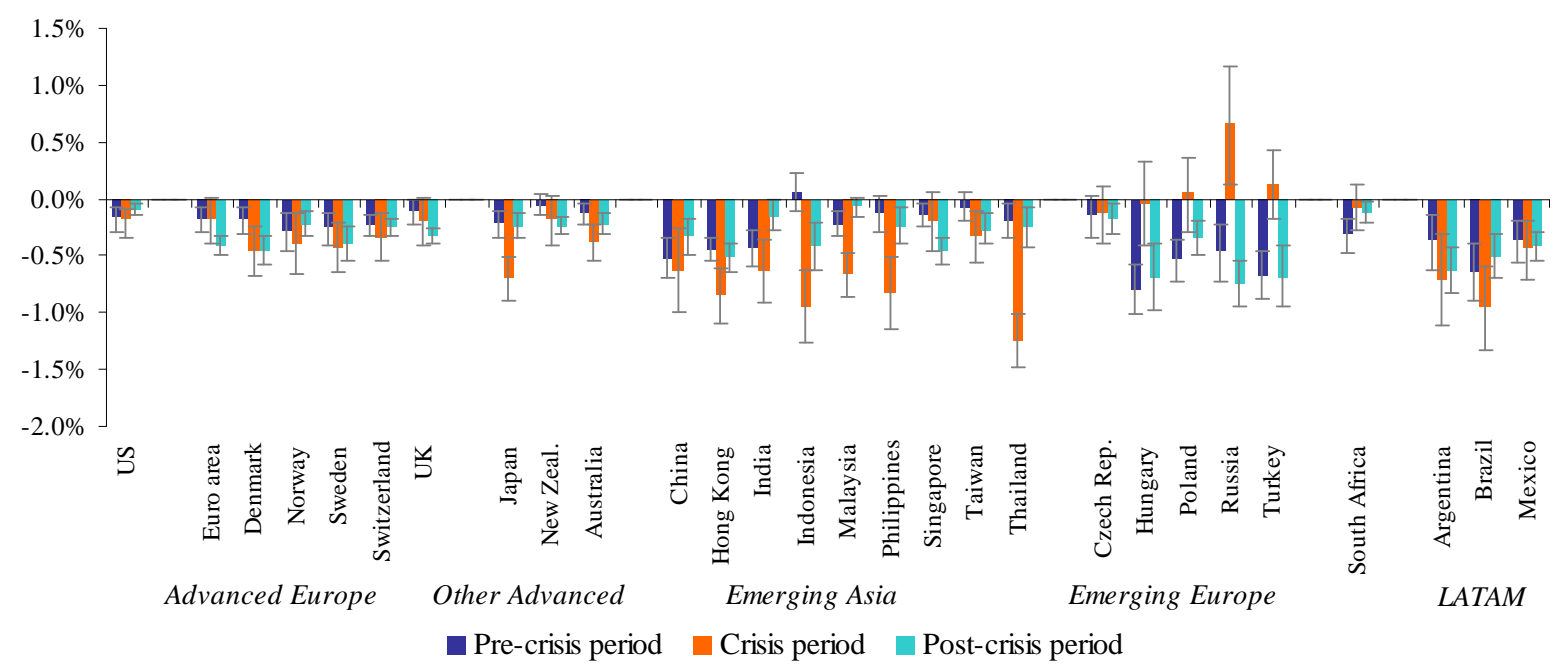

Figure A.16: Contemporaneous impact of one unit liquidity shock on equity markets in different countries with $25 \%-75 \%$ bootstrap bounds. 


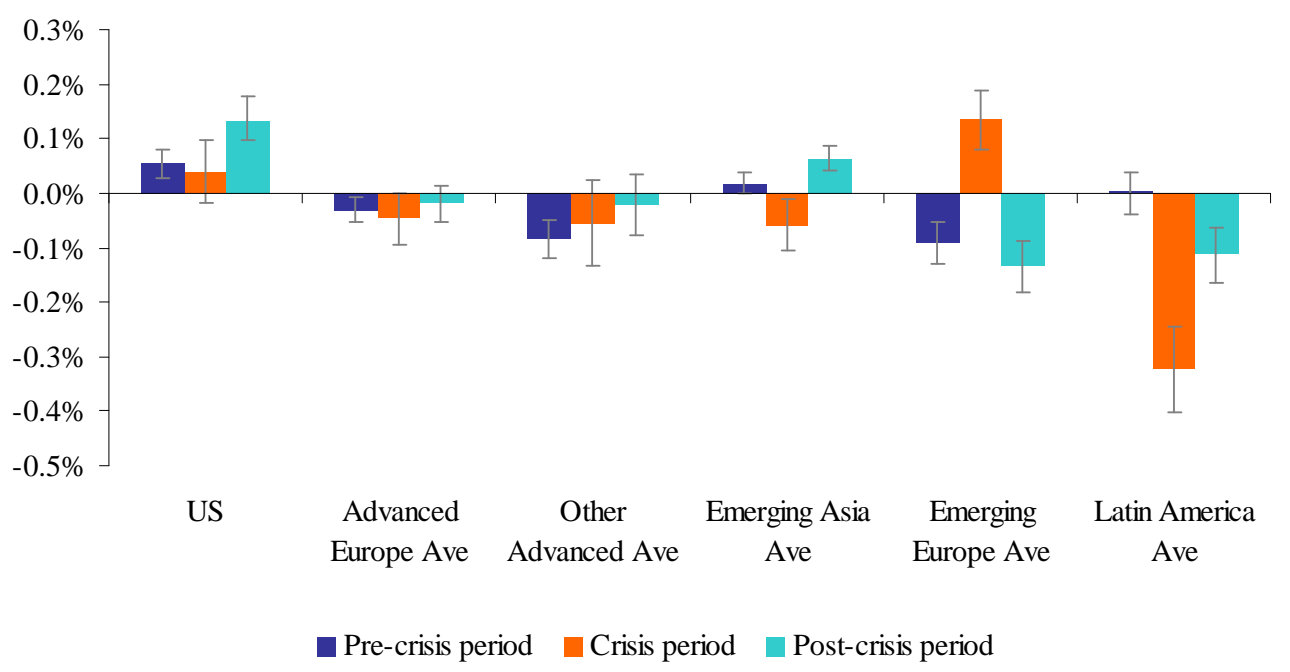

Figure A.17: Contemporaneous impact of one unit liquidity shock on foreign exchange markets in different regions with $25 \%-75 \%$ bootstrap bounds.

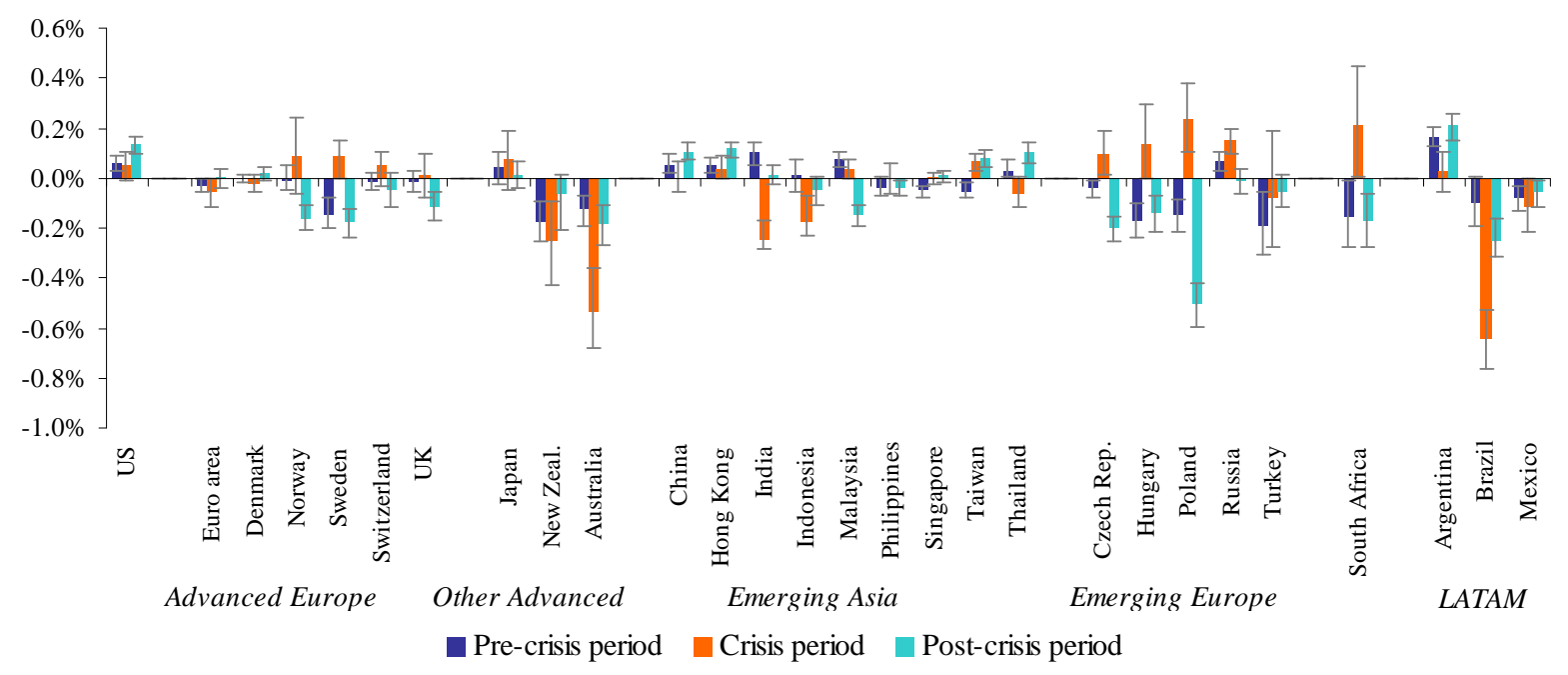

Figure A.18: Contemporaneous impact of one unit liquidity shock on foreign exchange markets in different countries with 25\%-75\% bootstrap bounds. 


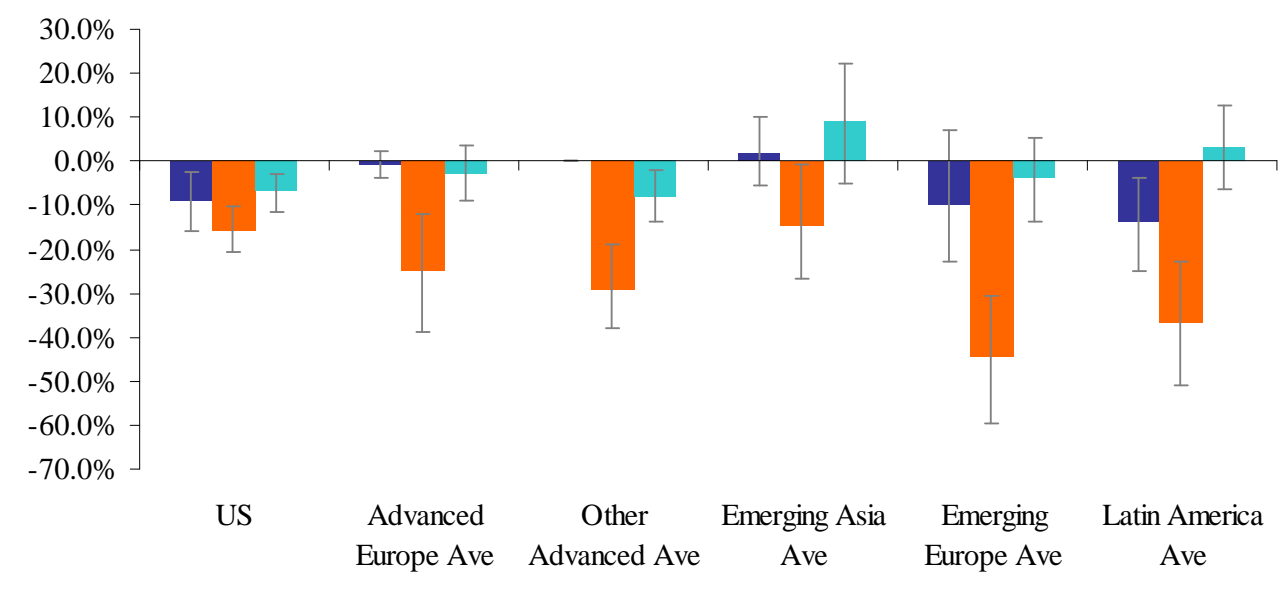

Pre-crisis period $\square$ Crisis period $\square$ Post-crisis period

Figure A.19: Cumulative impact of one unit liquidity shock on bond flows after 4 weeks in different regions with 25\%-75\% bootstrap bounds.

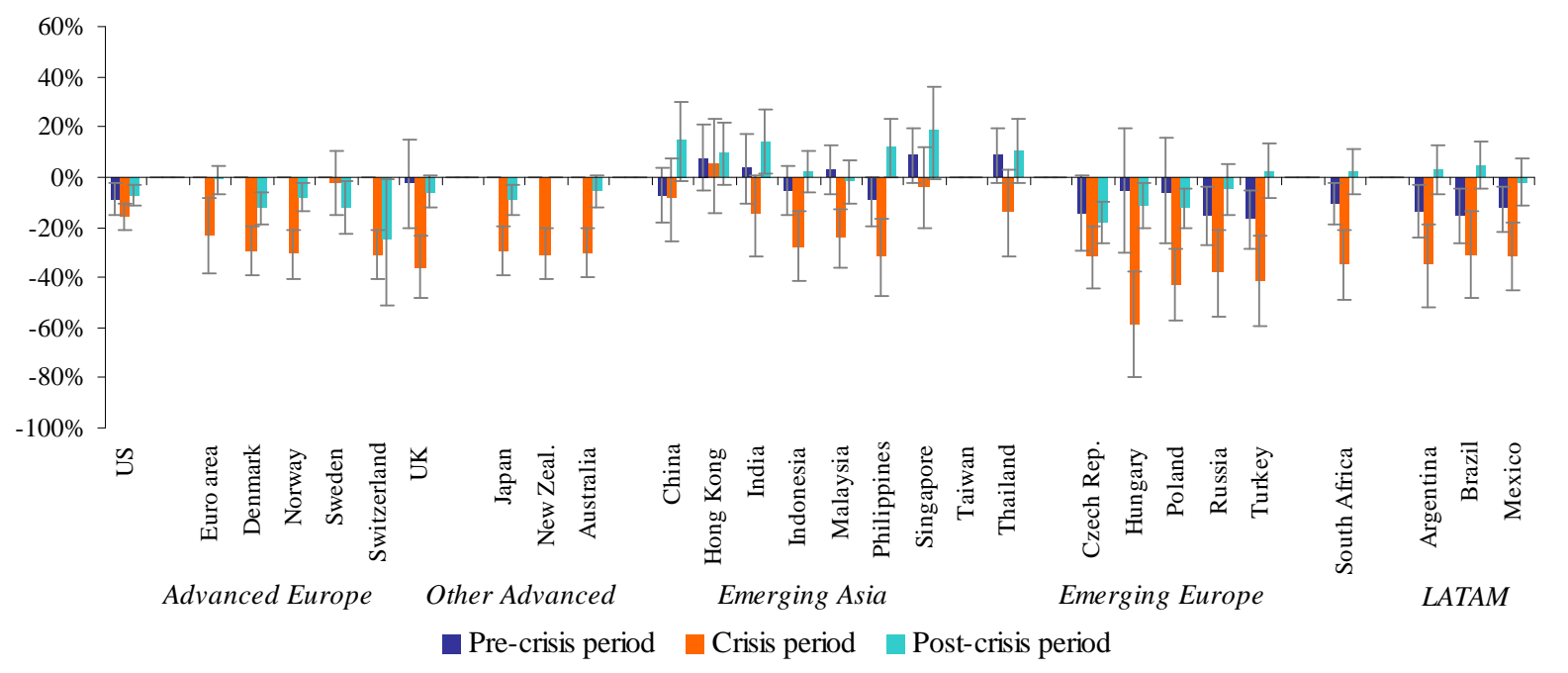

Figure A.20: Cumulative impact of one unit liquidity shock on bond flows after 4 weeks in different countries with $25 \%-75 \%$ bootstrap bounds. 


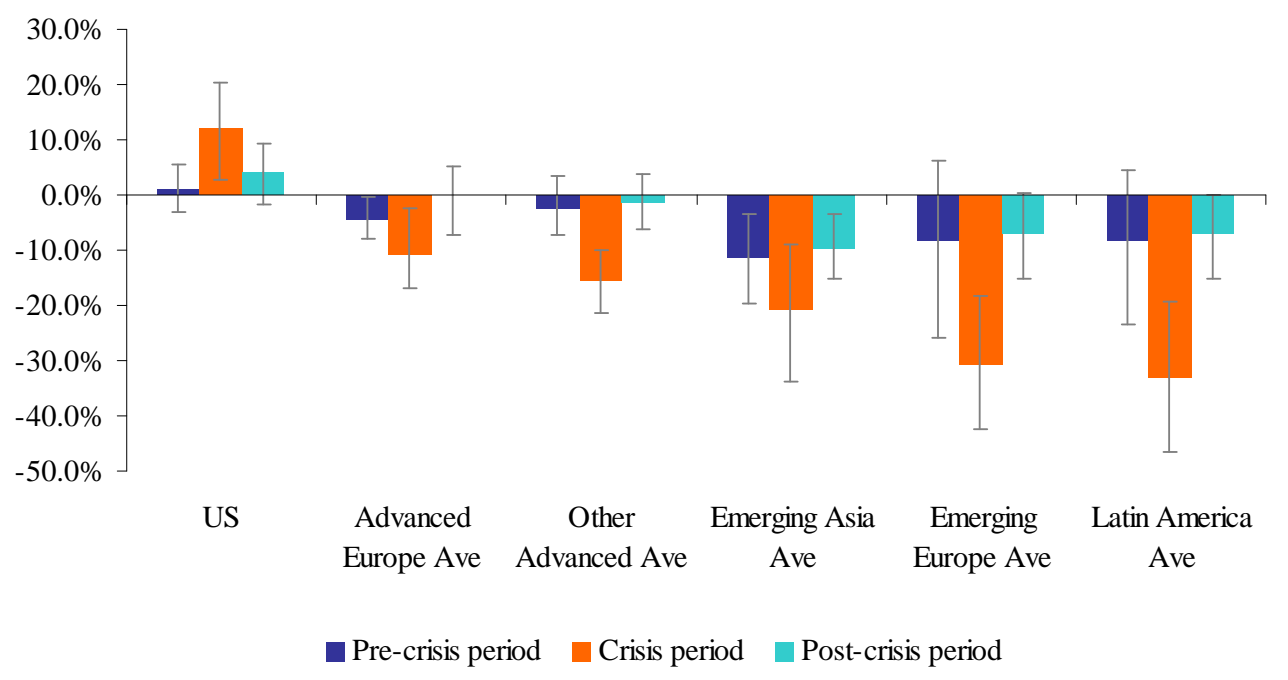

Figure A.21: Cumulative impact of one unit liquidity shock on equity flows after 4 weeks in different regions with $25 \%-75 \%$ bootstrap bounds.

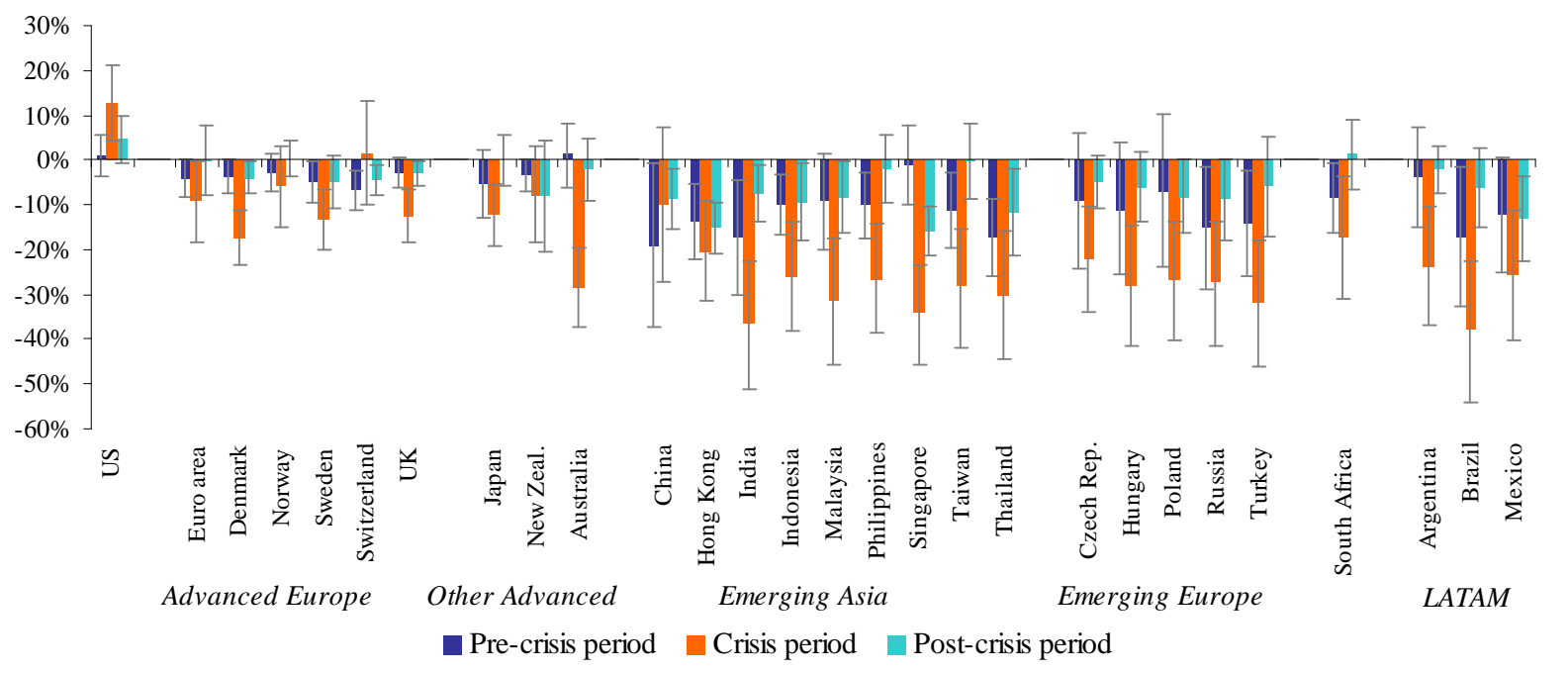

Figure A.22: Cumulative impact of one unit liquidity shock on equity flows after 4 weeks in different countries with $25 \%-75 \%$ bootstrap bounds. 


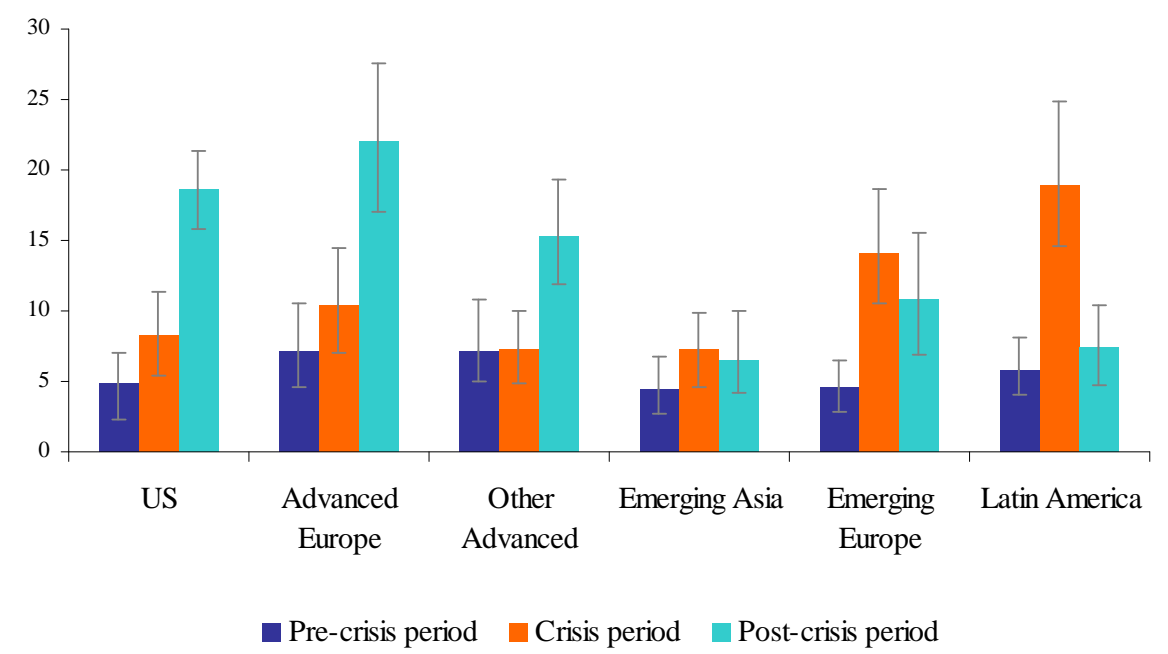

Figure A.23: Variance decompositions: risk shock as a driver of bond market returns (one-week ahead).

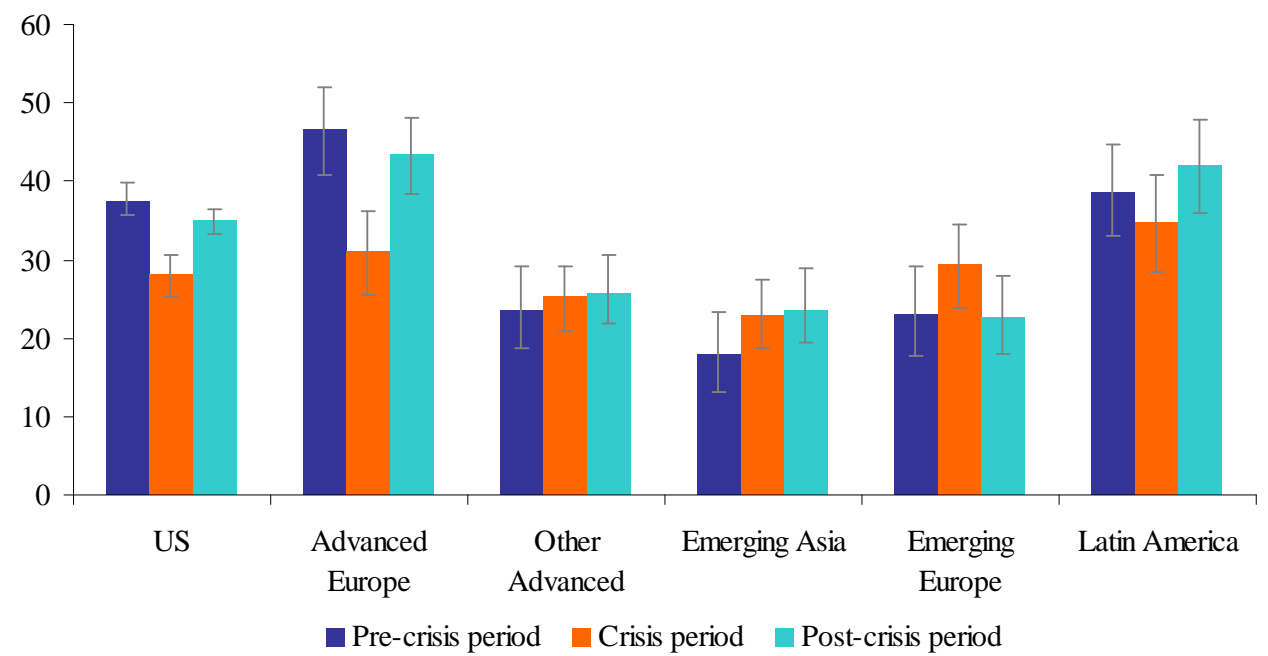

Figure A.24: Variance decompositions: risk shock as a driver of equity market returns (one-week ahead). 


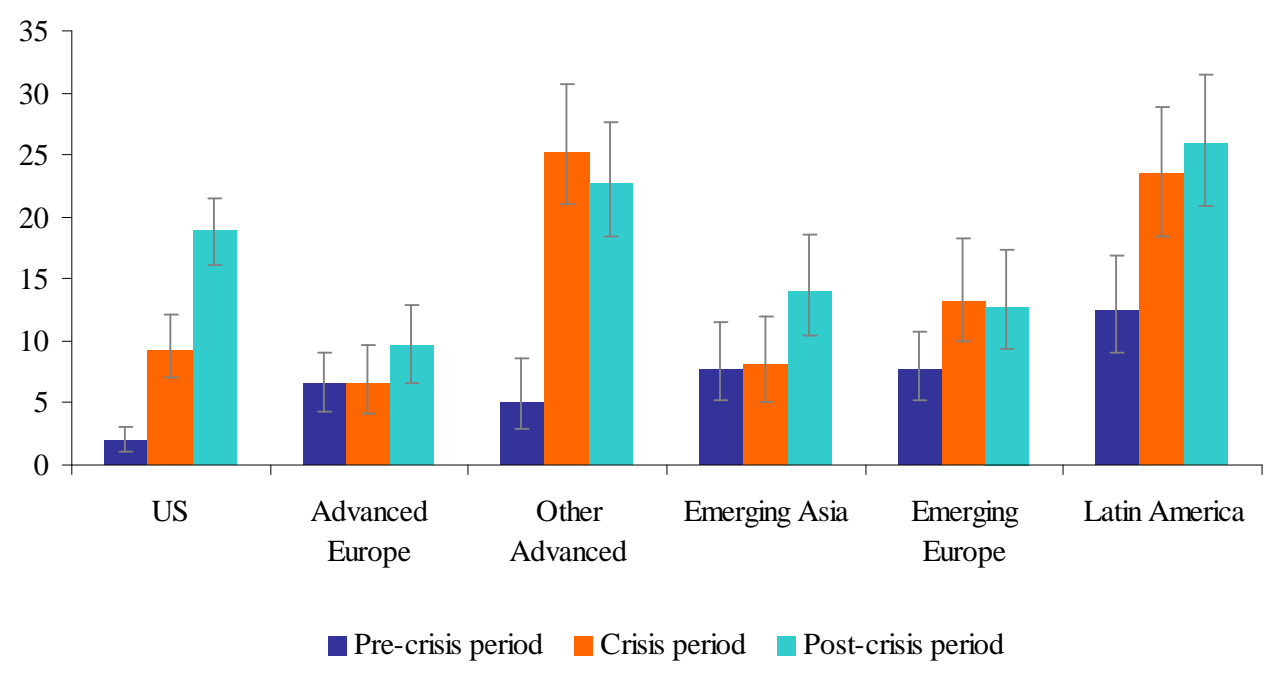

Figure A.25: Variance decompositions: risk shock as a driver of foreign exchange market returns (one-week ahead).

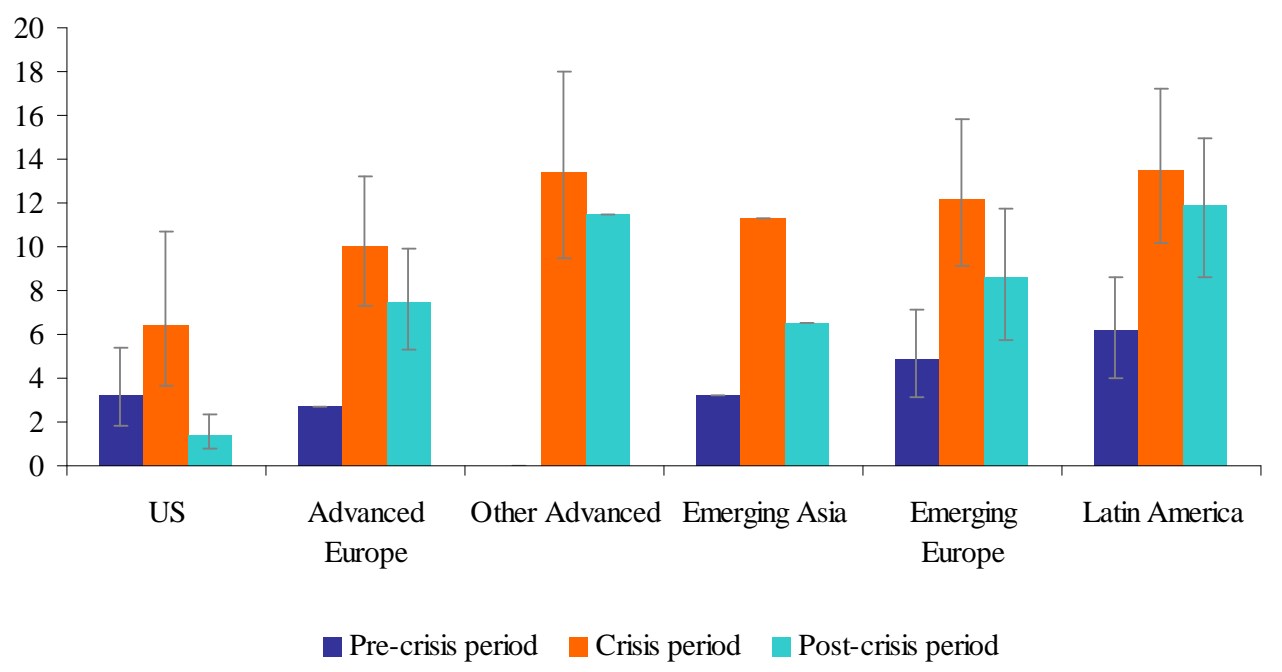

Figure A.26: Variance decompositions: risk shock as a driver of bond flows (four-weeks ahead). 


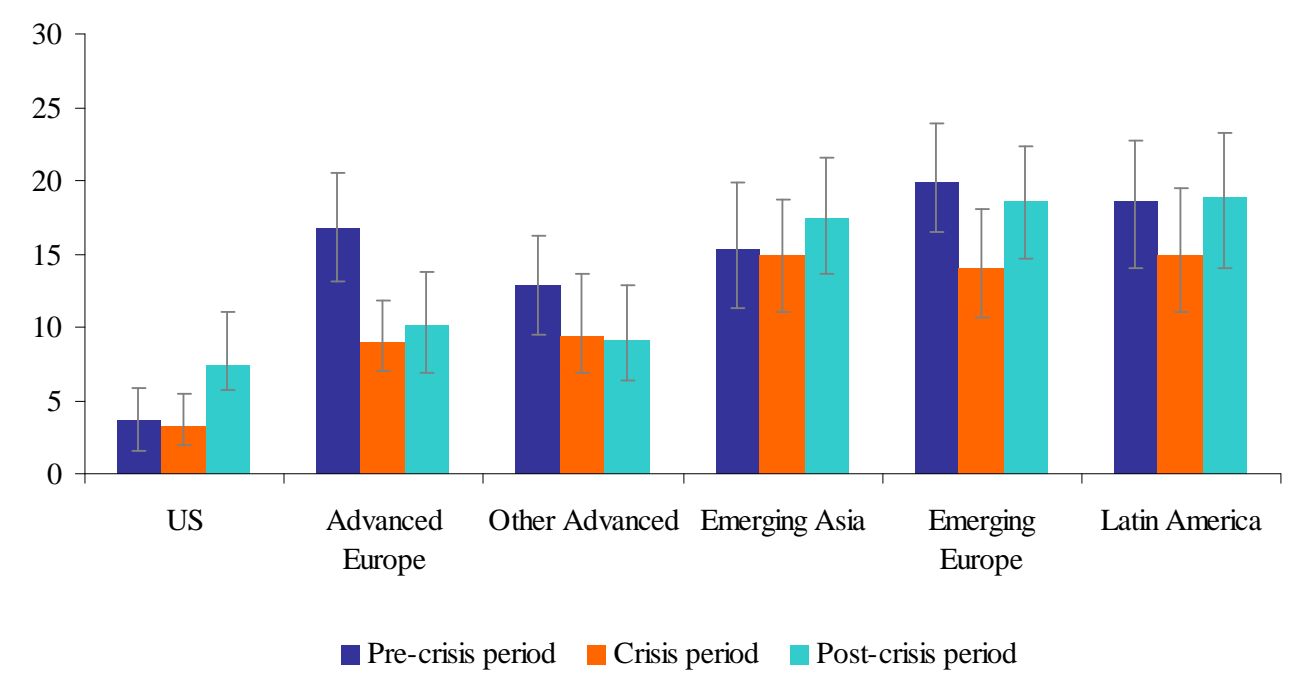

Figure A.27: Variance decompositions: risk shock as a driver of equity flows (four-weeks ahead). 